Article

\title{
The BioSCWG Project: Understanding the Trade-Offs in the Process and Thermal Design of Hydrogen and Synthetic Natural Gas Production
}

\author{
Mohamed Magdeldin ${ }^{1, *}$, Thomas Kohl ${ }^{1}$, Cataldo De Blasio ${ }^{1,2}$, Mika Järvinen ${ }^{1}$, \\ Song Won Park ${ }^{3}$ and Reinaldo Giudici ${ }^{3}$ \\ 1 Department of Mechanical Engineering, School of Engineering, Aalto University, Aalto FI-00076, Finland; \\ thomas.kohl@aalto.fi (T.K.); cataldo.de.blasio@aalto.fi (C.D.B.); mika.jarvinen@aalto.fi (M.J.) \\ 2 Department of Chemical Engineering, Åbo Akademi University, Turku 20500, Finland \\ 3 Department of Chemical Engineering, Universidade de São Paulo, São Paulo 05508-010, Brazil; \\ sonwpark@usp.br (S.W.P.); rgiudici@usp.br (R.G.) \\ * Correspondence: mohamed.magd@aalto.fi; Tel.: +358-41-470-7014
}

Academic Editor: Thomas E. Amidon

Received: 29 August 2016; Accepted: 29 September 2016; Published: 18 October 2016

\begin{abstract}
This article presents a summary of the main findings from a collaborative research project between Aalto University in Finland and partner universities. A comparative process synthesis, modelling and thermal assessment was conducted for the production of Bio-synthetic natural gas (SNG) and hydrogen from supercritical water refining of a lipid extracted algae feedstock integrated with onsite heat and power generation. The developed reactor models for product gas composition, yield and thermal demand were validated and showed conformity with reported experimental results, and the balance of plant units were designed based on established technologies or state-of-the-art pilot operations. The poly-generative cases illustrated the thermo-chemical constraints and design trade-offs presented by key process parameters such as plant organic throughput, supercritical water refining temperature, nature of desirable coproducts, downstream indirect production and heat recovery scenarios. The evaluated cases favoring hydrogen production at $5 \mathrm{wt}$. \% solid content and $600{ }^{\circ} \mathrm{C}$ conversion temperature allowed higher gross syngas and $\mathrm{CHP}$ production. However, mainly due to the higher utility demands the net syngas production remained lower compared to the cases favoring BioSNG production. The latter case, at $450{ }^{\circ} \mathrm{C}$ reactor temperature, $18 \mathrm{wt}$. $\%$ solid content and presence of downstream indirect production recorded $66.5 \%, 66.2 \%$ and $57.2 \%$ energetic, fuel-equivalent and exergetic efficiencies respectively.
\end{abstract}

Keywords: supercritical water gasification; lipid extracted algae; polygeneration; synthetic natural gas (SNG); hydrogen; thermodynamic assessment

\section{Introduction}

The recent announcement at the conclusion of the Paris 2015 United Nations Climate Change Conference, signed by more than 190 countries, recognized the irreversible negative impact on the environment by predating and existing industrialization. The adapted emission mitigation pledges and green energy policy frameworks signaled the growing global awareness and emphasis on the need for environmentally-conscious human progress and development [1]. Bio-based primary energy sources are considered a renewable source of carbon suitable to replace fossil fuel consumption, and have the additional potential, due to photosynthetic activity, to act as an emission sink within a carbon balanced life-cycle. As of today, biomass only constitutes around $10 \%$ of the global primary energy consumption, mainly in the form of traditional heat generation. However, it is expected to expand 
into a more integral role within the envisaged environmentally-sustainable energy and chemicals production sectors, as part of a future emission-constrained economy [2].

Bioenergy production and utilization, in both its traditional and more developed sense, 2nd and 3rd generation biofuels, includes the thermo- and bio-chemical transformation of solid feedstocks into a broader range of secondary energy carriers. In addition to electricity and heat as traditional coproducts, a variety of liquid and gaseous fuels or bio-chemical materials can be synthesized as part of future poly-generative bio-refinery concepts. Several interlinked socio-economic barriers and environmental concerns restrict the wider deployment and market penetration of the envisaged systems. However, some of the main challenges and drawbacks remain at heart of technical nature; such as resource efficient processing and integration within existing infrastructure, both of which could be addressed through the advancement of innovative conversion technologies [2,3].

Hydrothermal treatment is one of such technologies that has garnered significant attention within scientific and industrial circles in more recent years, especially the supercritical water gasification (SCWG) process. Here, the solid carbonaceous feedstock is subjected to pressurized aqueous processing, near to- and beyond the critical point of water at $374{ }^{\circ} \mathrm{C}$ and 221 bar. At such acute conditions, above the vapor pressure of water, the organic constituents of biomass are decomposed and valorized into a wider range of value added products. Extensive reviews on technology progress, the advantageous nature of supercritical water's chemical and physical properties and the up-to-date research findings can be found in the publications of Yakaboylo et al. [4], Akiya et al. [5], Kruse et al. [6,7], Brunner [8], Loppinet-Serani et al. [9], Knez et al. [10], Peterson et al. [11] and many others.

Yakaboylo et al. [4] identified the varying properties of viscosity, density and dielectric constant of water around the critical point as the main reason behind it's suitability for biomass refining. Liquid water (at $25^{\circ} \mathrm{C}$ and 1 bar), when upgraded into supercritical conditions, loses its characteristically polar tendency due to the destabilization of hydrogen bonds and, the acquirement of vapor-like density, density dependent di-electric constant and ionic product $k_{\mathrm{w}}$ properties [4,5]. Kruse [6] summarized it as "in biomass conversion processes [ ... ] water (in supercritical form) fulfills every possible role it is able to fulfill: It is solvent, catalyst or catalyst precursor, and reactant". The non-polar nature as well as the richer medium of $\left[\mathrm{H}_{3} \mathrm{O}\right]^{+}$and $[\mathrm{OH}]^{-}$ions in supercritical water allows for higher miscibility, selective reactive medium and homogenous processing for the organic constituents without significant mass or heat transfer limitations [5,7]. Inorganic or polar constituents of biomass on the other hand are relatively easily extracted, which fulfills many of the existing processing requirements. Brunner [8] in his review examined the various industrial applications in which the properties of supercritical fluids in general and for water specifically would provide a technical opportunity. The solubility of de-polymerized intermediates, some of which are char and tar precursors that account for conversion inefficiencies in more traditional processes, lead to higher recovery and utilization of the chemical energy initially stored within the solid feedstock. This feature was attributed by Loppinet-Serani [9] as the main motivation behind the current interest in SCWG and its already commercially available and energetically self-sufficient sister application of supercritical water oxidation (SCWO). The latter which is utilized for the degradation and destruction of organic and toxic sludge in water or agro-industrial waste treatment facilities.

Knez et al. [10] classified hydrothermal treatment on the basis of the selected processing temperature and as a result the predominant yield nature, a similar approach has been adapted in other works as well $[4,7,11-13]$. It is worth noting that the organic structure, solid-to-water ratio, residence time, pressure, catalysis and process units' mechanical configurations also influence the specific yields of each product as has been reported [4-6,9,11,13-16]. However, such information available in literature is diverse and fragmented, and temperature levels remain the governing processing parameter that identify the product phase distribution.

Under subcritical conditions (pressures from 20 to 200 bar):

(1) At lower temperatures-up to $250{ }^{\circ} \mathrm{C}$ : the product is primarily a carbon rich solid commonly known as hydro or bio-char and is reported to be as energetically dense as lignite [4]. 
(2) At higher temperatures-up to $400{ }^{\circ} \mathrm{C}$ : a de-oxygenated liquid commonly known as bio-oil or biocrude is the main product, accompanied with an aqueous stream with organic soluble compounds, a carbon dioxide rich gas and solid char residue as coproducts [11,17]. The bio-oil, consisting mainly of hydrolyzed organics, with a carbon partitioning as high as $40-45 \mathrm{wt}$. \% per carbon feed, has a heating value that could reach between 24 and $37 \mathrm{MJ} / \mathrm{kg}$ and offers a potential substitute for existing liquid fuels. However, it has been reported that significant upgrading is required to adjust the liquid viscosity levels for longer storage periods and match the lower oxygen and nitrogen content normally found in the corresponding petroleum crude products [15].

Under supercritical conditions (pressures beyond 221 bar):

(1) At lower temperatures-from 370 to $550{ }^{\circ} \mathrm{C}$ : under non-catalytic conditions, water soluble organics are the primary product. While with the introduction of either metallic or alkali based catalysts, a carbon rich syngas is released due to further de-polymerization, dehydration, dehydrogenation and decarboxylation reactions taking place. The product gas consists primarily of a carbon dioxide and methane mixture $[5,7,11]$.

(2) At higher temperatures-beyond $550{ }^{\circ} \mathrm{C}$ : catalytic and non-catalytic conditions yield a hydrogen rich syngas, as a result of kinetically driven gas reforming reactions [15]. Some literature has reported experimental results that show complete partitioning and conversion of carbon from model compounds or from catalyzed real biomass feedstocks into syngas at temperatures around $600{ }^{\circ} \mathrm{C}$ and beyond [16].

The appeal for hydrothermal treatment methods does not stem only from the higher organic conversion rates and selective product nature, but also from thermal design considerations. Yoshida et al. [18], carried out a comparative assessment between hydrothermal and the more traditional processes such as pyrolysis and thermal gasification. The group showed that for power production solely and for a combined heat and power (CHP) configuration, SCWG has a higher overall heat utilization or thermal recovery for carbon feedstocks with a moisture content higher than $40 \%$ and $30 \%$ respectively. This is attributed to the elimination of the pretreatment drying load which significantly leads to higher overall process efficiency. Although higher quality of heat and power demand, compared to traditional drying, are required to upgrade the processing medium into supercritical conditions, a quiet similar enthalpy change is required for both cases. Also, aqueous processing allows for the recovery of high quality heat more efficiently compared to the release of water vapor at lower temperatures in the traditional drying process. Another significant consideration is the potential to reduce component sizing and by proxy, lower associated production costs with the reduced processing volumes. The increased reactivity leads to significantly reduced reaction time, from a magnitude of hours to seconds, when compared to biochemical processes such as anaerobic digestion, commonly applied for high moisture feedstocks [19].

As such, a review of the state-of-the-art and an attempt to construe the thermal design trade-offs through conceptual process design, synthesis and modelling of the SCWG process has been the focus of a recent collaboration project between the Department of Mechanical Engineering (previously Department of Energy Technology) at Aalto University in Finland and the University of São Paulo in Brazil between 2012 and 2015. Earlier publications [20,21] have presented the developed reactor models and conceptual plant designs for envisaged integrated bio-refinery concepts for the production of chemical fuel-either BioSNG or hydrogen, heat and power from an algal feedstock. This article provides a comparative assessment between the high temperature-hydrogen production and the lower temperature-BioSNG favorable production pathways. The third partner of the project, Åbo Akademi University have investigated the hydrothermal treatment of black liquor and some of its model compounds, their main findings and contributions are reported in another recent publication [16]. 


\section{State of the Art}

\subsection{Supercritical Water Gasification Process Synthesis and Simulation}

\subsubsection{Supercritical Water Gasification Reactor Model}

The industrial realization and commercial introduction of an innovative technology is typically based on the development of pilot and demonstration projects (assumed here to have a nominal flow higher than $10 \mathrm{~kg}$ solid matter per hour), some of which are already in place for the SCWG application [22,23]. From which, technical knowledge in the form of collected operational data would offer reliable guidance for equipment scale up. However, experimental data remains limited to conditional settings; adjustment to variables of the original setup would lead to deviations during implementation, especially for parametric sensitive, and chemically complex and energy intensive processes such as supercritical water refining (SCWR) [15]. Due to the absence of detailed and generally accepted kinetics for processing different heterogeneous structures within the hydrolyzed aqueous mixtures, thermodynamic modelling is the alternative approach for process assessment. Thermodynamic equilibrium modelling is commonly divided in literature into two types; stoichiometric and non-stoichiometric [4]. The first approach, as the name implies, requires a clearly defined and balanced set of reactions. The computation of the equilibrium constant of each reaction leads to a multivariable optimization problem to be solved in order to obtain yield and product nature at defined conditions. The work of Marias et al. [24] applied a stoichiometric model for a parametric assessment of a SCWG reactor and a subsequent pressurized phase separator. A predefined set of 7 independent reactions within a single supercritical phase was assessed to represent the principal organic conversion step, as well as the thermal quality of dry product syngas from the separator. On the other hand, the non-stoichiometric models are based on the principle of Gibb's free energy minimization. The developed models do not require definite knowledge of the detailed chemical transformations, and as such are widely applied to SCWR processes [4]. The reactions are handled with a black box approach where the only information required are the elemental input and the expected chemical composition of products [11].

Several published works attempted to derive mathematical models that showed conformity with experimental findings in literature to enable extended parametric assessments for product nature [25-30]. Others utilized commercial computational software equipped with more extensive databases of property data banks for a wider list of chemical species [31-40]. Louw et al. [31] used the process simulation tool Aspen Plus ${ }^{\mathrm{TM}}$ (Aspen Technology, Inc., Bedford, MA, USA) to screen a comprehensive list of 49 real biomass and 5 model compounds. A simplistic plant model that consisted of a SCWG reactor and subsequent phase separator, for direct dry syngas production was investigated. Susanti et al. [32] and Tushar et al. [33] followed suit for the investigation of some expected organic monomers or intermediates in the SCWG process. However, the scope of their assessment was not on system-level thermal analysis but rather on deconstructing the specific organic conversion pathways and predict some of the driving forces for reaction kinetics only.

The principal challenge to ensure the development of a reliable reactor or process model remains the computation of the specific thermodynamic properties of the highly asymmetric and multi-dimensional slurry mixtures. The parametrization of the SCWR phase equilibria interactions for the various processing components of solid and fluid phases, polar and non-polar in nature, within super- and sub-critical conditions remains an area under development [41]. As such, predictive empirical equations of states (EOS) have garnered significant attention over recent years for SCWG assessment studies. The advantage of empirical EOS in general compared to their activity coefficient counterparts is the ability to predict phase equilibria at elevated pressures where infinite dilution in a single phase is experienced [41]. Some of the EOS adapted in literature are the Peng-Robinson (PR) $[24,26,28,31,32,35]$, Soave Redlich Kwong (SRK) [36,38], Duan [27,40], Statistical Association Fluids Theory (SAFT) [25], Virial EOS [30] and the original ideal package [33]. Some authors employed 
hybrid approaches to account for inaccuracy of some models, Gassner et al. [40] employed a hybrid Duan-Lee Kesler modelling approach for their BioSNG production case. The first EOS reportedly parametrized for tertiary $\mathrm{CH}_{4}-\mathrm{CO}_{2}-\mathrm{H}_{2} \mathrm{O}$ mixtures and the second is utilized to account for inconsistent enthalpy estimation of the Duan equation. Lu et al. [27] also derived a hybrid approach with Duan and SRK, with the latter employed due to reported higher accuracy for phase equilibria prediction for a wider set of mixtures that include $\mathrm{H}_{2}$. Withag et al. [36] attempted to compare a list of 6 PR and SRK based EOS combinations with non-quadratic mixing rules, and reported a bandwidth of deviation for molar hydrogen prediction below 3.5\% for all. However, Ortiz et al. [38] examined the accuracy of the predictive SRK EOS for enthalpy prediction, and reported a slight deviation for organic- $\mathrm{H}_{2} \mathrm{O}$ mixtures, which would be amplified with a high water throughput in SCWR. Valderrama [41] in his review of different cubic EOS reiterated that a hybrid approach, that considers integrated excess Gibbs energy models (a non-quadratic mixing rule) within empirical EOS parameters remains necessary to offer more reliable equilibria data for non-ideal mixtures with a supercritical component. The PR EOS integrated with the Wong Sandler (WS) mixing rule was recommended as it accounts for residual enthalpy. It is worth mentioning that this approach was one of the examined EOS for the SCWG process by Withag et al. [36]. Table 1 lists a summary of up to date publications on process simulation approaches for SCWG reactor models, as well as proposed conceptual plant layouts, which are described in detail in the following section.

\subsubsection{Conceptual Supercritical Water Gasification Bio-Refinery Design}

The concept of a bio-refining system is akin to petroleum refining and poly-generative energy generation, in which, a diversified set of products with higher quality in both a material and thermal sense are extracted from the carbon rich feedstock. The higher organic recovery and chemical versatility of the SCWG process enables it to be synthesized as the core conversion step in envisaged bio-refineries. The earliest reports in literature for real biomass processing in supercritical water conditions was that of Modell et al. in 1985 [14]. However, to the author's knowledge, the pioneering work of the late Antal Jr. and his group at the Hawaii Natural Energy Institute was the first attempt to present the influence of process design configurations for a SCWG unit on plant viability. In their U.S. Department of Energy (DOE) sponsored hydrogen production project, which later published the findings in 1999 [15], the group investigated various SCWG reactor slurry types, feeding methods, reactor geometries and orientations, heating methods and wall material configurations. The work acknowledged the chemical equilibrium constraints of the SCWG to produce a high purity hydrogen gas, with the highest experimental yield reported at $2 \mathrm{~L}$ gas per $\mathrm{g}$ of solid feed with a purity of up to $57 \%$ hydrogen only. As a result, the development of post treatment units for commercially acceptable end-of-the-pipe SCWG products has been investigated by several research groups recently. 
Table 1. List of all SCWG process simulation and conceptual plant modelling projects reported in literature to the authors' knowledge (as of 31 December 2015).

\begin{tabular}{|c|c|c|c|c|c|c|c|}
\hline Reference & Feedstock & SCWG Conditions & $\begin{array}{l}\text { End of Pipe } \\
\text { Product }\end{array}$ & $\begin{array}{c}\text { Modelling Tool \& } \\
\text { Approach }\end{array}$ & $\begin{array}{c}\text { EOS for Supercritical } \\
\text { Properties }\end{array}$ & $\begin{array}{c}\text { Inorganic } \\
\text { Modelling }\end{array}$ & Energy Recovery Assessment \\
\hline Louw et al. [31] & $\begin{array}{c}-5 \text { model } \\
\text { compounds } \\
-49 \text { real biomass }\end{array}$ & $\begin{array}{l}\text { 600, } 700 \& 800{ }^{\circ} \mathrm{C} ; 221 \mathrm{bar} ; \\
5,15 \& 25 \text { wt. \% solids }\end{array}$ & $\begin{array}{l}\text { Reactor model } \\
\quad \text { only }\end{array}$ & $\begin{array}{l}\text { Aspen Plus } \\
\text { NS-GM }\end{array}$ & PR-BM $^{1}$ & No & $\begin{array}{l}\text { Isothermal reactor demand } \\
\text { was assessed. }\end{array}$ \\
\hline Susanti et al. [32] & $\begin{array}{l}\text { a list of } C_{1} \text { to } C_{16} \\
\text { model compounds }\end{array}$ & $\begin{array}{l}650 \& 740{ }^{\circ} \mathrm{C} ; 250 \mathrm{bar} ; \\
10 \& 20 \text { wt. \% solids }\end{array}$ & $\begin{array}{l}\text { Reactor model } \\
\text { only }\end{array}$ & $\begin{array}{l}\text { Aspen Plus }{ }^{\mathrm{TM}} \\
\text { NS-GM }\end{array}$ & PR & No & Not considered. \\
\hline Tushar et al. [33] & $\begin{array}{l}\text { - glucose } \\
\text { - furfural } \\
\text { - phenol }\end{array}$ & $\begin{array}{l}700^{\circ} \mathrm{C} ; 280 \text { bar; } \\
5 \text { wt. } \% \text { solids }\end{array}$ & $\begin{array}{l}\text { Reactor model } \\
\text { only }\end{array}$ & $\begin{array}{l}\text { Aspen Plus }{ }^{\mathrm{TM}} \\
\text { NS-GM }\end{array}$ & Ideal package & No & Not considered. \\
\hline Feng et al. [25] & - cellulose & $\begin{array}{l}600^{\circ} \mathrm{C} ; 350 \text { bar; } \\
20 \text { wt. } \% \text { solids }\end{array}$ & High purity $\mathrm{H}_{2}$ & Not reported & SAFT & No & $\begin{array}{c}\text { Recuperated heat and } \\
\text { combustion of non- } \mathrm{H}_{2} \text { syngas. }\end{array}$ \\
\hline Lu et al. [27] & - wood sawdust & $\begin{array}{l}600 \text { to } 1100{ }^{\circ} \mathrm{C} ; 250 \mathrm{bar} ; \\
5 \text { to } 30 \text { wt. } \% \text { solids }\end{array}$ & High purity $\mathrm{H}_{2}$ & Not reported & Duan & No & Recuperated heat. \\
\hline Gasafi et al. [34] & - sewage sludge & $\begin{array}{l}600^{\circ} \mathrm{C} ; 280 \text { bar; } \\
20 \text { wt. } \% \text { solids }\end{array}$ & High purity $\mathrm{H}_{2}$ & Not reported & $\mathrm{N} / \mathrm{A}^{2}$ & No & $\begin{array}{l}\text { Recuperated heat, combustion } \\
\text { of non- } \mathrm{H}_{2} \text { and auxiliary gas. }\end{array}$ \\
\hline Fiori et al. [35] & $\begin{array}{c}\text { - glycerol } \\
\text { - microalgae } \\
\text { - sewage sludge } \\
\text { - grape marc } \\
\text { - phenol }\end{array}$ & $\begin{array}{l}500,700 \& 900{ }^{\circ} \mathrm{C} ; 300 \text { bar; } \\
5 \text { to } 25 \text { wt. } \% \text { solids }\end{array}$ & Power & $\begin{array}{l}\text { Aspen Plus } \\
\text { NS-GM }\end{array}$ & PR-VdW 3 & No & Combustion of non- $\mathrm{H}_{2}$ syngas. \\
\hline Withag et al. [36] & $\begin{array}{l}\text { - methanol } \\
\text { - cellulose }\end{array}$ & $\begin{array}{l}400 \text { to } 800{ }^{\circ} \mathrm{C} ; 100 \text { to } 400 \mathrm{bar} ; \\
5 \text { to } 35 \mathrm{wt} \text {; } \% \text { solids }\end{array}$ & $\begin{array}{c}\text { Dry gas } \\
\text { Captured } \mathrm{CO}_{2}\end{array}$ & $\begin{array}{l}\text { Aspen Plus }{ }^{\mathrm{TM}} \\
\text { NS-GM }\end{array}$ & SRK-MHV2 ${ }^{4}$ & No & Recuperated heat. \\
\hline Galera et al. [37] & - glycerol & $\begin{array}{l}800^{\circ} \mathrm{C} ; 240 \text { bar; } \\
26 \text { wt. } \% \text { solids }\end{array}$ & Power & $\begin{array}{l}\text { Aspen Plus }{ }^{\mathrm{TM}} \\
\text { NS-GM }\end{array}$ & PSRK $^{5}$ & No & Heat exchanger network-HEN. \\
\hline Aziz et al. [39] & - Spirulina algae & $\begin{array}{c}700^{\circ} \mathrm{C} ; 220 \text { to } 300 \text { bar; } \\
10 \text { wt. } \% \text { solids }\end{array}$ & Power & $\begin{array}{l}\text { SimSci PRO/II } \\
\text { NS-GM }\end{array}$ & Not reported & No & Exhaust heat from CC turbines. \\
\hline Gassner et al. [40] & $\begin{array}{l}\text { - generalized waste } \\
\text { biomass }\end{array}$ & $\begin{array}{l}350 \text { to } 450^{\circ} \mathrm{C} ; 300 \mathrm{bar} ; \\
10 \text { to } 20 \mathrm{wt} . \% \text { solids }\end{array}$ & Grid quality $\mathrm{CH}_{4}$ & $\begin{array}{c}\text { Belsim SA } \\
\text { Not reported }\end{array}$ & Duan—Lee Kesler & Yes & Different Scenarios evaluated. \\
\hline SunCHem concept [42-44] & - microalgae & $\begin{array}{l}400^{\circ} \mathrm{C} ; 250 \text { bar; } \\
15 \text { wt. } \% \text { solids }\end{array}$ & Grid quality $\mathrm{CH}_{4}$ & Not reported ${ }^{7}$ & N/A & Yes & $\begin{array}{l}\text { Recuperated heat and split } \\
\text { combustion of } \mathrm{CH}_{4} \text { product. }\end{array}$ \\
\hline \multicolumn{8}{|c|}{$\begin{array}{l}\text { Notes: }{ }^{1} \text { Different EOS property methods for supercritical processing were assessed, and PR-BM was selected for the reactor model based on reported higher accuracy; }{ }^{2} \text { Stoichiometric } \\
\text { conversion of glucose model compound was the basis for reactor modelling, under the assumption of complete conversion of organics to syngas }\left(\mathrm{H}_{2}-\mathrm{CH}_{4}-\mathrm{CO}_{2}\right) \text { and complete } \\
\text { precipitation of inorganics; }{ }^{3} \text { Fiori et al. [35] did not report the EOS used in simulation, however in the groups' earlier work [29], in which the reported conceptual design was based, } \\
\text { the authors used the PR-VdW EOS; }{ }^{4} \text { Examined seven combinations of PR and SRK based EOS with different mixing rules; the authors reported only a } 3 \% \text { variation in the upper limit } \\
\text { of } \mathrm{H}_{2} \text { yield predictions; }{ }^{5} \text { The simulation model used the PSRK EOS while no mixing rule was reported, the Holderbaum-Gemehling mixing rule for supercritical mixtures was } \\
\text { reported in the group's earlier work [38]; }{ }^{6} \text { Equilibrium conditions for SCWG were based on previous experimental results with a ruthenium catalyst, however the modelling approach } \\
\text { was not specifically reported; }{ }^{7} \text { Algal conversion and yield data for the model were based on experimental findings reported in one of the publications [43]. Abbreviations. Modelling } \\
\text { tool \& approach: NS-GM: non stoichiometric minimization of Gibbs free energy; EOS for Supercritical properties: PR-Peng Robinson, SAFT--statistical association fluid theory, } \\
\text { SRK-Soave Redlich Kwong, PSRK-Predictive Soave Redlich Kwong, VdW-Vander Wall mixing rule, MHV2-modified Huron Vidal mixing rule, HG-Holderbaum-Gemehling } \\
\text { mixing rules and BM-Boston-Mathias modifications for mixtures. SCWG-Supercritical Water Gasification, EOS-Equation of state. }\end{array}$} \\
\hline
\end{tabular}


It is accepted that through the fine-tuning of the reactive conditions and subsequent unit configurations, the SCWG process could be either designed for BioSNG production under catalytic, low temperature and higher solid content conditions [21,36,40,42-44] or for hydrogen under high temperature, lower solid content and longer residence times [15,20,25,27,34,35,37-39,45]. Another critical design question, aside from maximizing conversion to the desired product within the reactor system, is the development of a thermal recovery system to minimize the higher thermodynamic quality heat and power demand of the core conversion step taking place under supercritical conditions. Feng et al. [25] presented one of the earlier plant layouts in literature that considered thermal recovery. The design extended the conditions within a commissioned subcritical hydrothermal upgrading (HTU) pilot plant for bio-crude production into supercritical processing. It is worth mentioning that the proposed design of subsequent syngas upgrading to high purity $\mathrm{H}_{2}$; through the utilization of pressurized water phase equilibria properties for $\mathrm{CO}_{2}$ capture and followed by a $\mathrm{H}_{2}$ membrane separator, were first reported by the group then adapted later within several publications. The residue gases from the upgrading steps were burned for heat recovery purposes, while the deficit heat and power were supplied through wood fueled units. The reported thermal efficiency of the plant layout was around $41 \%$. Lu et al. [27] proposed a similar design while replacing the final membrane separator step with a pressure swing adsorption (PSA) unit to achieve fuel cell quality hydrogen of $99.99 \%$ purity and below 5 ppm CO content. The design adapted by Gasafi et al. [34] for their economic assessment of an envisaged sewage sludge treatment plant, introduced an auxiliary pressurized water scrubber before the $\mathrm{H}_{2}$ separation units. The additional unit was a mean for complete recovery of dissolved $\mathrm{CO}_{2}$ within the liquid water effluent through in situ dissolution. This was later iterated by Ji et al. [45] in their attempt to optimize the synthesis processes for syngas purification. The group concluded that hydrogen purity in the extracted dry syngas is maximized with a higher water to gas ratios. However, it is worthwhile to mention that this presents another design tradeoff with regards to product hydrogen partitioning. The more recent published work of Yakaboylu et al. [46] was also based on the envisaged design by Feng et al. [25], albeit a more comprehensive multi-phase modelling approach investigated the influence of elemental salts and their inorganic compounds on the design of product extraction steps.

Other groups investigated thermal self-sufficient operational conditions for a SCWG reactor through different process plant configurations. Fiori et al. [35] attempted to identify self-sufficient organic slurry concentrations with different feedstocks for a reactor system tuned for a $\mathrm{H}_{2}$ rich gas product at $700{ }^{\circ} \mathrm{C}$ and 300 bar. The thermal demand of the plant, which reportedly only took into consideration the SCWG reactor load, was fulfilled through recuperated heat from the reactor outlet and the combustion of non $\mathrm{H}_{2}$ product syngas. Meanwhile power demand for pressurizing the feed was met with either expansion of the compressed syngas or through a hydrogen driven proton exchange membrane (PEM) fuel cells. The reported concentrations, which presumably would yield enough by-product syngas for heat and power recovery, were $22.9 \mathrm{wt}$. \% for sewage sludge, $20.5 \mathrm{wt}$ \% for glycerol, $18.3 \mathrm{wt}$. \% for Spirulina microalgae, $16.6 \mathrm{wt}$. \% for grape marc and $11.4 \mathrm{wt}$. \% for phenol. The Withag et al. group [36] investigated the SCWG process with subsequent carbon capture for both $\mathrm{CH}_{4}$ (at $400{ }^{\circ} \mathrm{C}$ ) and $\mathrm{H}_{2}$ (at $600{ }^{\circ} \mathrm{C}$ ) rich syngas. The heat deficit for sustaining the optimized isothermal reactor operations was met through combustion of split syngas produced or auxiliary $\mathrm{CH}_{4}$. The authors attempted to correlate self-sufficient thermal processing of the reactor system with the effectiveness of recuperated heat from the reactor outlet. $20 \mathrm{wt}$. \% and $25 \mathrm{wt}$. \% solid content for methanol and cellulose feedstocks respectively were required for a reactor thermal efficiency of $70 \%$ with a practically realistic heat exchanger effectiveness of $80 \%$.

The reported work of Galera et al. [37] and Ortiz et al. [38] developed detailed heat exchanger networks for a synthesized glycerol to power and/or $\mathrm{H}_{2}$ gas plant as part of an ongoing effort to establish new valorization means for the glycerol byproduct from existing biodiesel industry. Two heat recovery options were considered; the combustion of a produced syngas split or a partially oxidized reactor configuration. Based on the group's findings, both systems recorded almost identical energetic 
efficiency and net $\mathrm{H}_{2}$ production. To investigate power production purposes solely, Aziz et al. [39] proposed a catalyzed fluidized bed SCWG reactor system for a spirulina algae feedstock, as the solid conversion step in an integrated gasification combined cycle excess power integration (IGCC-EPI) configuration. The integrated design presented several thermal synergies, where heat demand for the SCWG reactor was delivered from the gas turbine cycle's high temperature exhaust and feed preheating demand partially provided by dissipated heat from the steam cycle. The overall plant energetic efficiency was reported in the range of $37 \%-58 \%$ for different fluidized bed velocities within the SCWG unit.

Other novel designs that considered BioSNG production from SCWG were proposed and developed by members of the Paul Scherrer Institute (PSI) and the École Polytechnique Fédérale de Lausanne (EPFL) in Switzerland [40,42-44,47]. A microalgae to BioSNG layout labeled SunCHem [43], included catalytic processing around $400{ }^{\circ} \mathrm{C}$, for higher overall thermal efficiencies, to produce a mixture of $\mathrm{CH}_{4}$ and $\mathrm{CO}_{2}$, with the first further upgraded to grid quality BioSNG and the latter sequestered to yield a net-negative carbon lifecycle balance. The group investigated several life cycle cultivation options [42,47] and proposed both nutrient recycling and the utilization of flue gas $\mathrm{CO}_{2}$ from existing power plants. Earlier work reported by Gassner et al. [40], constructed a techno-economic optimization model for a grid-quality BioSNG production superstructure, for generalized waste biomass feedstock. A three step reactor system was synthesized: a subcritical hydrolyzer, a salt separator around the critical point and a catalytic reformer at $400{ }^{\circ} \mathrm{C}$, followed by a screening for possible downstream upgrading technologies and energy recovery options based on the overall system's energetic and exergetic efficiencies.

\subsection{Algal Biomass Case Study}

Microalgae is an ideal feedstock candidate by design and intuition for hydrothermal treatment processes. The minimal solid content offers an opportunity for aqueous processing without additive water. The processing requirements for more traditional thermal applications generally lead to an overall negative energy balance [48,49], which is mainly attributed to the feedstock pretreatment requirements for such high moisture content, which could reach up to $99.9 \%$. Meanwhile, physical or mechanical dewatering, which has a lower thermal penalty than drying as a pretreatment step, yields a solid substrate of around 10-20 wt. \%. This range falls within the existing commercial slurry pump-ability range $[17,42,50]$ and based on recent life cycle assessment studies reported in literature for hydrothermal processing, would result in a net positive-producer/energy valorization system [12,42,47-49,51-54].

When compared to other energy crops under development, algae's higher photosynthetic efficiency and specific area yields allow for higher specific energy production compared to that of lignocellulosic based crops [52]. Another advantage over terrestrial biomass, currently commercialized for bio-ethanol production [2], is the ability to avoid the potential competition with food production demand over arable land. Algae's flexibility for cultivation conditions extends to brackish and higher saline mediums. Microalgae in specific could be cultivated within either open ponds or closed photo-bioreactors $[2,12,42,49]$, however most cultivation systems for energy production have yet to reach commercial status [2,48]. Although at first, research was focused on the extraction of the algae's lipid content for biodiesel production, the suitability of hydrothermal processing for whole algal cell conversion, including both carbohydrates and proteins, enables higher carbon and therefore enhanced energy recovery $[48,54,55]$. It is worth mentioning that algal hydrothermal treatment systems are still considered to be at a lab and pilot level development stage. A review on some of the most recent reported experimental investigations can be found in Reference [20]. Also, Elliot [48] recently provided a technical review on the up to date development of algal hydrothermal facilities globally and reported that any commercial scale-up is expected to involve technical and logistical challenges which would require higher productions costs than those currently realized. 
From a system design perspective, hydrothermal treatment attempts to exploit the properties near-to the critical point of the algal water substrate for extraction and recycling of nitrogen and phosphorus nutrients, necessary for cultivation. Ekpo et al. [13] showed that up to $90 \%$ of nitrogen was recovered in the aqueous phase at $350{ }^{\circ} \mathrm{C}$ and more than $97 \%$ at $500{ }^{\circ} \mathrm{C}$, with only less than $10 \%$ of nitrogen detected in hetero form. Elliot et al. [15] claimed that $50 \%$ of the nitrogen demand for cultivation purposes could be recovered by the aqueous recycling. Considering that, along with algae's high $\mathrm{CO}_{2}$ sequestration rate, developers have recently envisaged holistic closed cycle designs with recycled nutrients and captured $\mathrm{CO}_{2}$ from industrial systems and power plants [43,47,51-53]. However, one design challenge reported for the recycled nutrients streams is the continued presence of growth inhibitors in the form of phenolic rings, due to intermediate organic re-polymerization as well as amino acid compounds' incomplete conversion. Further processing and treatment was recommended before final introduction into the cultivation environment [53].

In this present study, we examine the conversion of lipid extracted algae (LEA), post biodiesel production, for an integrated onsite CHP configuration along with synthetic gas, either BioSNG or hydrogen, for offsite power and chemicals production. The conceptual bio-refinery, envisages a poly-generative energy structure, with a lower carbon footprint than a whole algae stand-alone hydrothermal plant as reported in literature [54]. The elemental analysis for the plant's solid feedstock used in this study is provided in Table 2, and is based on averaged data reported in the Phyllis2 database of the Energy Centre of Netherlands (ECN) for a broad range of lipid extraction methods [56].

Table 2. Elemental analysis of the lipid extracted algae feedstock for the developed study cases, from the Energy Centre of Netherlands Phyllis2 database [56].

\begin{tabular}{cccc}
\hline Proximate Analysis, wt. \% (as Received Basis) & Ultimate Analysis, wt. \% (Dry Ash Free Basis) \\
\hline Ash content & 4.59 & Carbon & 50.99 \\
Moisture & 5.62 & Hydrogen & 7.44 \\
Volatiles & 75.34 & Oxygen & 33.61 \\
Fixed carbon & 14.45 & Sulfur & 0.48 \\
& & Nitrogen & 7.48 \\
\hline
\end{tabular}

\section{Developed Conceptual Plant Designs}

A simplified block representation of the envisaged BioSNG and hydrogen production pathways is shown in Figure 1. From the left, at the LEA feedstock entry point, the block diagram illustrates the sequential common upstream processing steps for both production pathways, which principally convert the solid organic content into dry sweet syngas. At first, solid valorization takes place under SCWR conditions within blocks A1-3, shown in light green. This is followed by the extraction of the SCWG product water content and acid gases $\left(\mathrm{CO}_{2}\right.$ and $\left.\mathrm{H}_{2} \mathrm{~S}\right)$ removal, in blocks $\mathrm{B} 1$ and $\mathrm{B} 2$ respectively, shown in shades of blue. The directly produced SCWG product is a mixture of $\mathrm{H}_{2}, \mathrm{CH}_{4}$ and $\mathrm{CO}_{\mathrm{x}}$, excluding water, whose concentrations depend on the operating conditions of the SCWG reactor. A parametric analysis for a similar LEA feedstock was reported in our earlier publication [20]; where the theoretical maximum or equilibrium limit for $\mathrm{CH}_{4}$ purity in dry syngas at supercritical processing of $400{ }^{\circ} \mathrm{C}, 250$ bar and $15 \mathrm{wt}$. \% solid content was only $51.5 \mathrm{~mol} \%$. Meanwhile for hydrogen, the upper limit at $600{ }^{\circ} \mathrm{C}, 5 \mathrm{wt}$. $\%$ solid content and a similar pressure was $59.3 \mathrm{~mol} \%$. As a result, downstream blocks, C1-2 and D1-2, were designed for further syngas upgrading to meet the desirable properties for the two final products; Finnish grid quality BioSNG injection and $99.99 \%$ purity hydrogen as a minimum requirement for chemical industrial purposes or fuel cell power generation systems [35,37]. 


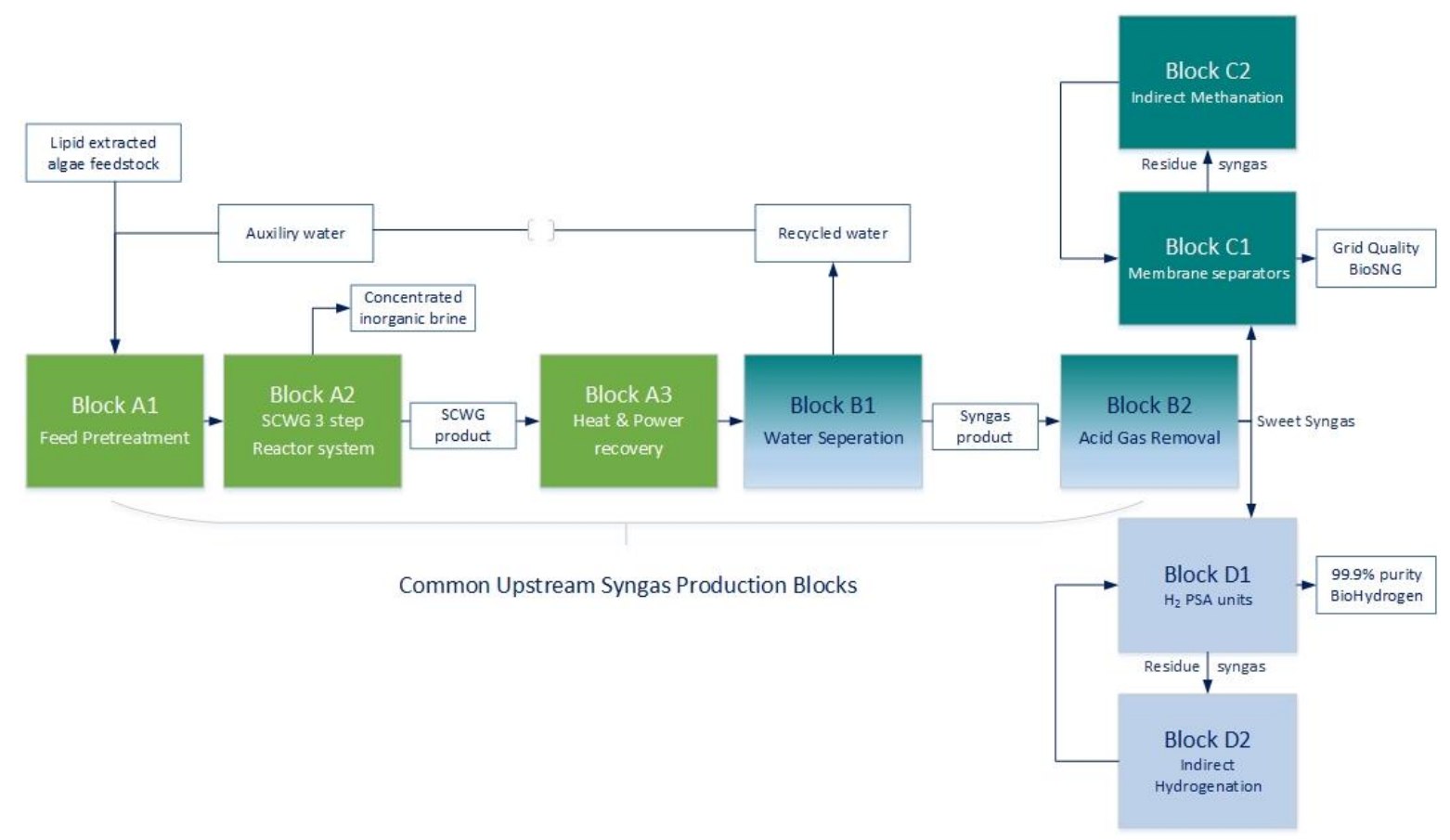

Figure 1. Simplified block diagram for the envisaged lipid extracted algae hydrothermal treatment to Bio- synthetic natural gas and hydrogen production pathways.

The complete plant layouts were simulated on the commercial software Aspen Plus ${ }^{\mathrm{TM}}$. The thermodynamic property package Peng Robinson Wong Sandler (PRWS) was selected for units operating near to and beyond supercritical processing, namely within blocks A2 and A3. The PRWS was selected due to its reported higher accuracy for phase equilibria estimations for asymmetric and/or polar-nonpolar and/or supercritical mixtures as is the case with biomass SCWR [41]. While the Predictive Soave Redlich Kwong (PSRK) was used for subcritical to ambient processing units. The thermo-physical properties of solid content in LEA were defined as a non-conventional compound and estimated based on software built-in coal database correlations HCOALGEN and DCOALIGT in Aspen Plus ${ }^{\mathrm{TM}}$. The gross and net heating values of 22.95 and $21.23 \mathrm{MJ} / \mathrm{kg}$ on dry ash free basis are similar to those reported in literature elsewhere [20,56].

\subsection{Common Upstream Syngas Production Blocks}

Upstream operations consist of five processing steps; pretreatment-A1, supercritical refining-A2, heat and power recovery-A3, syngas drying-B1 and acid gas removal-B2. At first, in block A1, the LEA slurry is homogenized by solid content adjustment, particle size reduction and mixing. Aside from eluding pumping challenges and clogging during slurry processing, the physical pretreatment steps lead to increased accessibility to the organic pores, and as a result enhanced hydrolysis and fragmentation. The slurry is then pressurized to 250 bar by means of a five stage rotary lobe pumping system, selected from a compiled list of commercial vendors available in literature [50], and then further preheated to $350{ }^{\circ} \mathrm{C}$.

\subsubsection{Three Step Supercritical Water Refining Reactor System}

The thermally elevated slurry enters the three step reactor system, designed to exploit the versatile and advantageous properties of supercritical water for biomass refining. At first, under subcritical conditions, the solid biomass is fragmented and decomposed under highly ionic conditions into a hydrolyzed mixture of hundreds of organic compounds [11]. The multiphase product consists of a hydrophobic organic crude phase, a water soluble organic phase along with solid residue and $\mathrm{CO}_{2}$ rich 
gas. The operation at a slightly higher than critical pressure level aims to maintain aqueous processing into the second stage salt separator $[17,40]$. It is important to note, that an advantage of the gasification design route over the simpler cutoff bio-crude liquefaction route, is the possibility to directly recover more of the carbon partitioned in the multiphase hydrolyzed product, rather than only carbon captured in the hydrophobic crude phase [54]. The hydrolyzed product is then introduced and simultaneously heated to around the critical point of water $\sim 380^{\circ} \mathrm{C}$ in a salt separator vessel. The processing principal is based on the patented concept at the Paul Scherrer Institute (PSI) [40] to precipitate the insoluble polar inorganics at the bottom of the vessel with a conservative $10 \mathrm{wt}$ \% organic loss as brine, while a polar supercritical reverse flow exits from the top. The organic rich supercritical flow is then fed into a reformer/gasifier, at which an ionic rich (at lower temperatures) or radical rich medium (at higher temperatures) drives organic kinetic transformation into the syngas rich SCWG product [5].

A detailed description of the three step reactor model-block A2 on Aspen Plus ${ }^{\mathrm{TM}}$ is shown in Figure 2 below. The organic conversion of the user defined non-conventional solid feedstock was assessed with a combined approach of two software built-in units; first a decomposer (HYDREAC) into elemental constituents and valorizer (SCWGREAC) into the pre-defined set of products consisting of; methane, hydrogen, carbon dioxide, carbon monoxide, water, ethane, ethylene, solid carbon, phenol, nitrogen, ammonia and hydrogen sulfide. A similar approach was adapted in other reported publications and showed conformity with experimental data [31,35]. The net reactor demand (NETDMND) along with interstage heating (STGDMND) thermal streams account for both the net endothermic heat of formation of products and the sensible heat requirement for the interstage heating independently. The salt separator (SALTSEP) is simulated as a standard separator unit, where the solubility of elemental constituents dictates the unit thermal requirements. The separator is set to a conservative $10 \%$ organic slurry loss within the extracted inorganic brine, similar to that reported in literature [40,47].

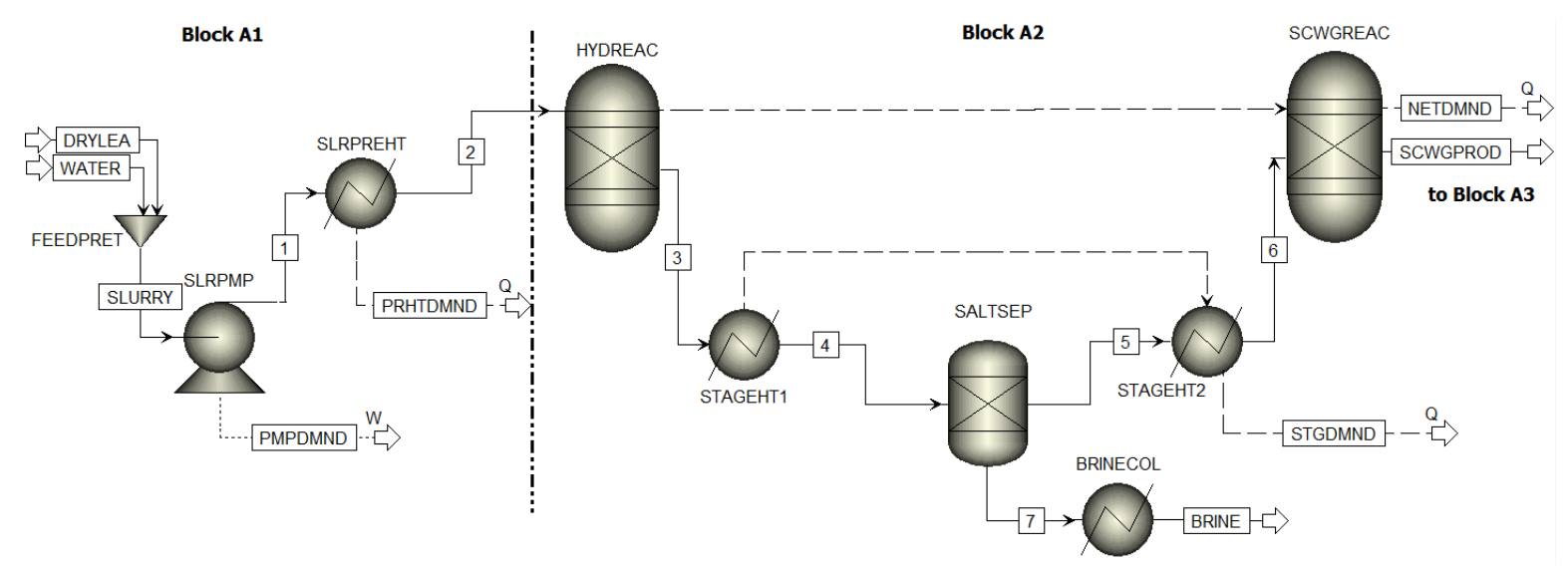

Figure 2. Flowsheet of the Aspen Plus ${ }^{\mathrm{TM}}$ simulation model for blocks A1-2. Legend: Solid lines are material streams while dotted lines are heat and power loads. Units: FEEDPRET: physical pretreatment unit, SLRPMP: slurry pump, SLRPRHT: preheater, HYDREAC: hydrolysis reactor, STAGEHT1: inter-stage heater/salt separator jacket, SALTSEP: salt separator unit, STAGEHT2: inter-stage heater to gasification conditions, BRINECOL: solid effluent cooler and SCWGREAC: the gasifier.

\subsubsection{Product Recovery Blocks}

The SCWG product then enters block A3 for heat and power recovery purposes. At first, the stream is fed into a supercritical expander, simulated in a similar way to commercial ultra-supercritical steam (USC) expanders. The expanded stream exits at 65 bar with an isentropic efficiency of $92.5 \%$ and is then further cooled to ambient conditions. In commercial USC applications, the turbine outlet is further reheated and expanded for maximal power recovery. However, as power is only a coproduct and not the targeted final product, several downstream processing advantages favor maintaining the 
elevated pressure conditions [37]. The pressurized aqueous stream allows for significant $\mathrm{CO}_{x}$ capture through dissolution, as well as the elimination of downstream recompression loads for gas upgrading purposes or to meet grid specifications in the BioSNG cases [40].

As such, the pressurized cooled product stream is fed into a two stage knockout $(\mathrm{KO})$ drum configuration in the water separation block B1. The first stage at 60 bar is used to separate the dry syngas product, while the liquid effluent is further flashed at 1 bar for the recovery of recycled water along with a $\mathrm{CO}_{2}$ rich depleted gas. The separated dry syngas, rich in either $\mathrm{CH}_{4}$ or $\mathrm{H}_{2}$, has a significant $\mathrm{CO}_{2}$ concentration, normally from $30 \%$ to $40 \%$ [6], and is separated in the following acid gas removal step. The commercially deployed tertiary amine Methyldiethanolamine (MDEA) Selexol technology was selected; due to its higher $\mathrm{H}_{2} \mathrm{~S}$ selectivity, capability to completely dehydrate the feed, higher gas processing capacity and moderate energetic demand. The selective extraction of $\mathrm{CO}_{2}$ and $\mathrm{H}_{2} \mathrm{~S}$ is $96.5 \%$ and $91 \%$ respectively [21]. Meanwhile, off-gas released during solvent recovery, rich in hydrocarbons, is utilized for in-situ heat generation.

\subsection{Synthetic Natural Gas Production Pathway}

The sweetened syngas enters a sequential membrane separator system in block $\mathrm{C} 1$ to remove $\mathrm{H}_{2}$ and residue $\mathrm{CO}_{x}$ and nitrogen compounds, to meet the Finnish grid injection specification, shown in Table 3. The rejected membrane off-gases, consisting mostly of $\mathrm{H}_{2}$ and $\mathrm{CO}$, are mixed with depleted $\mathrm{CO}_{2}$ streams from blocks $\mathrm{B} 1$ and $\mathrm{B} 2$, and fed into an indirect methanation block $\mathrm{C} 2$ to boost plant production and minimize organic carbon loss under supercritical refining in the form of $\mathrm{CO}_{x}$. The block consists of a catalytic reverse water gas shift (RWGS) reactor to adjust the $\mathrm{H}_{2} / \mathrm{CO}$ ratio. The RWGS product is then fed into a catalytic methanation reactor, enriched with steam to avoid coke formation, to convert $\mathrm{CO}_{x}$ and $\mathrm{H}_{2}$ into $\mathrm{CH}_{4}$ and $\mathrm{H}_{2} \mathrm{O}$. The product is then dried and recycled back to block $\mathrm{C} 1$ for upgrading similar to that of directly produced $\mathrm{CH}_{4}$ for the additional production of BioSNG at grid quality specifications.

Table 3. Specification for grid injected bio based methane in Finland. Data obtained through discussions with local stakeholders.

\begin{tabular}{cc}
\hline Specification & Target \\
\hline Methane & $>96 \mathrm{~mol} \%$ \\
Carbon dioxide and nitrogen & $<2.5 \mathrm{~mol} \%$ \\
Hydrogen and carbonyl sulphide & $<5 \mathrm{mg} / \mathrm{Nm}^{3}$ \\
Carbon monoxide & $<0.05 \mathrm{~mol} \%$ \\
Hydrogen & $<2 \mathrm{~mol} \%$ \\
Oxygen & $<1 \mathrm{~mol} \%$ \\
Water content & $<3 \mathrm{mg} / \mathrm{Nm}^{3}$ \\
Wobbe Index & $13.76<x<15.81 \mathrm{kWh} / \mathrm{Nm}^{3}$ \\
Relative density & $0.555<x<0.700$ \\
\hline
\end{tabular}

\subsection{Hydrogen Production Pathway}

The sweet syngas from block B2 is expanded to 20 bar and then fed into a multistage PSA unit in block D1 for a $99.9 \%$ purity hydrogen product stream [27,37]. The PSA off-gas is either sent to an indirect hydrogenation block D2 or co-fired with other depleted streams for heat recovery purposes. In the first case, the $\mathrm{CH}_{4}$ rich gas is catalytically reformed, in the presence of steam to produce $\mathrm{H}_{2}$ and $\mathrm{CO}$, at $650{ }^{\circ} \mathrm{C}$ and 5 bar. In order to maximize the desired product, the stream is then fed into a two stage water gas shift (WGS) reactor, in which present $\mathrm{CO}$ is further converted to $\mathrm{H}_{2}$. The product is then dried and recycled back to block D1 for additional hydrogen production with a $99.99 \%$ purity. 


\subsection{Case Studies}

Four cases were selected for comparative assessment; two for each of hydrogen and BioSNG, as shown in Table 4. The dictating design considerations, as mentioned in Section 2, are the SCWG reforming temperature and plant solid throughput. For hydrogen production both, direct hydrogen and overall gasification yield increase with higher temperature and lower solid content. While for BioSNG, a design tradeoff is present between direct methane production at lower temperatures and higher overall gasification yield at higher temperatures. Several metal based catalysts have been proposed in literature to enhance gasification at lower temperatures, however several challenges related to catalyst deactivation have been reported $[4,11,40]$. An additional constraint for the SCWG outlet temperature by design, is the subsequent USC expander inlet conditions, at which commercial units are currently operational at approximately a temperature of $600{ }^{\circ} \mathrm{C}$. As such, for BioSNG, the two cases were selected at SCWG reforming temperatures of $600{ }^{\circ} \mathrm{C}$ and $450{ }^{\circ} \mathrm{C}$. With the lower limit of $450{ }^{\circ} \mathrm{C}$ considered a conservative estimate based on reported experimental data in literature, for the lowest possible gasification temperature at which carbon partitioning into syngas exceeds that of carbon losses within aqueous and solid phases. The inlet solid content for both cases was constrained by the operational limit of the selected slurry pump at $18 \mathrm{wt}$. \% solid content [50]. In the second BioSNG case at $450{ }^{\circ} \mathrm{C}$, the exclusion of the USC expanders in block $\mathrm{A} 3$ allows the assessment of the influence of power production within a CHP configuration on the internal heat recovery.

Table 4. Selected case studies for comparative assessment.

\begin{tabular}{ccccc}
\hline Design Condition & $\begin{array}{c}\text { Hydrogen } \\
\text { Base Case }\end{array}$ & $\begin{array}{c}\text { Hydrogen } \\
\text { 2nd Case }\end{array}$ & $\begin{array}{c}\text { BioSNG } \\
\text { Base Case }\end{array}$ & $\begin{array}{c}\text { BioSNG } \\
\text { 2nd Case }\end{array}$ \\
\hline Slurry solid conc., wt. $\%$ & 5 & 5 & 18 & 18 \\
SCWG reformer T, ${ }^{\circ}$ C & 600 & 600 & 600 & 450 \\
In-situ power production & Yes & Yes & Yes & No \\
In-situ indirect production & Yes & No & Yes & Yes \\
\hline
\end{tabular}

For the hydrogen production cases, in our earlier work [20], it was shown that for the case with more concentrated feedstock ( $18 \mathrm{wt}$. \% solid content) at higher temperatures of $600{ }^{\circ} \mathrm{C}$, despite thermal self-sufficient operation and coproduction of $\mathrm{CH}_{4}$ and $\mathrm{H}_{2}$, the case recorded lower overall efficiencies compared to the cases presented here that show a lower solid content of $5 \mathrm{wt}$. \%. This was attributed to the lower gasification rate within the SCWG reactor block along with the increased capacity for downstream upgrading for the two parallel gaseous products rich in $\mathrm{H}_{2}$ and $\mathrm{CH}_{4}$ respectively. In the present work, the two reported hydrogen cases maintain a favorable SCWG reformer temperature of $600{ }^{\circ} \mathrm{C}$ and a lower solid content of $5 \mathrm{wt}$. \% for hydrogen, while comparing the influence of indirect production block D2 on the overall plant thermal efficiency with respect to the BioSNG cases. The two BioSNG cases had the indirect downstream production block, as it allows to reduce carbon processing losses for SCWR in the form of $\mathrm{CO}_{2}$, which as a result enhances energy recovery while allowing the overall system to act as an emission sink.

\subsection{Conceptual Plant Evaluation}

The objective of this work is to identify the technical limitation of each production pathway and provide a comparative assessment based on thermal performance evaluators. As such, maximum internal heat recovery, as well as the minimum utility demand are calculated for each case with the pinch analysis method. The overall performance of each developed case is then assessed based on energetic, fuel-equivalent and exergetic conversion efficiencies. The energetic efficiency $\eta$ is calculated on a lower heating value (LHV) basis from solid biomass fuel to gaseous products, electricity and district heating, as follows: 


$$
\eta=\frac{\left(\dot{m} \cdot h_{L H V}\right)_{\text {product }}+W_{e l}+Q_{D H}}{\left(\dot{m} \cdot h_{L H V}\right)_{L E A}+\left(Q_{t h}\right)_{\text {external }}}
$$

where $\dot{m}$ and $h_{L H V}$ are the mass flow rates and lower heating value of the product syngas (BioSNG or hydrogen) and of the LEA feedstock. $W_{e l}$ is the net electricity generated onsite, $Q_{D H}$ is the onsite district heat generated and $\left(Q_{t h}\right)_{\text {external }}$ is the minimum thermal plant utility demand. The qualitative nature of products are further analyzed through both the fuel-equivalent, $\eta_{f u e l-e q}$ and exergetic efficiencies $\eta_{e x}$ shown below:

$$
\eta_{\text {fuel-eq }}=\frac{\left(\dot{m} \cdot h_{L H V}\right)_{\text {product }}+\left(W_{e l} \cdot\left(1 / \eta_{N G C C}\right)\right)+\left(Q_{D H} \cdot\left(1 / \eta_{\text {boiler }}\right)\right)}{\left(\dot{m} \cdot h_{L H V}\right)_{L E A}+\left(Q_{\text {th }}\right)_{\text {external }}}
$$

where, $\eta_{N G C C}=0.57$ represents the efficiency of a reference natural gas combined cycle and $\eta_{\text {boiler }}=0.9$ represents the efficiency for an industrial boiler. The factor accounts for the additional fuel saving quality of electricity and district heat production, a similar approach has been adopted broadly in literature [40].

$$
\eta_{e x}=\frac{E_{\text {product }}+W_{e l}+E_{D H}}{E_{L E A}+\left(1-T_{o} / T_{i}\right) \cdot\left(Q_{\text {th }}\right)_{\text {external }}}
$$

where $E_{\text {product }}$ represents the exergy recovered within products BioSNG and hydrogen, while $E_{L E A}$ is that of biomass feed and $E_{D H}$ is the exergy of the onsite district heating. $T_{o}$ and $T_{i}$ represent the temperatures of both the reference state and the average of which thermal utility was supplied respectively, calculations were adapted from Reference [57].

\section{Results and Discussion}

\subsection{Three Step Reactor Model Validation}

The SCWG product composition and yield of the developed reactor model was compared with those reported within experimental setups in literature. Different processing conditions were taken into consideration to assess model reliability in terms of accuracy, flexibility and reproducibility. The model results were compared to the work of Stucki et al. [44] for validation of the lower temperature conditions that favor direct BioSNG production, while the work of Chakinala et al. [52] was compared for hydrogen favorable conditions. A first look at the reported numbers in Table 5, illustrate the parametric sensitive nature of the direct SCWG process. As mentioned in the introduction, parameters such as pressure, temperature, solid concentration, residence time, organic structure and catalytic effect influence the level of carbon partitioning into the gas phase, as well as product gas composition. For a reliable comparison, all parameters, excluding both the residence time and catalytic effect, were set in the Aspen plus ${ }^{\mathrm{TM}}$ model similar to those reported for each experimental setup. Product gas data were collected after the removal of the water content at ambient conditions. The authors acknowledge that such an ideal separation, coupled with the assumption of thermodynamic equilibrium might lead to disparity from the experimental data. However, when the model was compared to data from experimental settings that achieve almost complete carbon gasification in Table 5, the findings show conformity for both lower and higher level operating temperatures. Yakaboylu et al. [58] attempted to introduce restricted or constrained parameters for the conversion of certain products (e.g., carbon and hydrogen gas yields) to account for how deviated the system is from a chemical equilibrium state. The group concluded that a globally developed model would still fall short on accuracy levels, as a finite amount of constraints are needed to account for process variations within each specific experimental setup. It is worth mentioning that carbon losses within our developed model, which acts as an organic conversion constraint, was in the range of $10 \%-13 \%$ across the different simulation runs and accounts for organic losses within the bottom exit brine in the salt separator, along with residues of $\mathrm{CO}_{x}, \mathrm{CH}_{4}$ and phenol found in effluent water. 
Table 5. Comparative assessment between the developed reactor model (shown in bold italic, adjacent to each case for $\mathrm{CH}_{4}$ and as the last column in $\mathrm{H}_{2}$ production) and experimental findings in literature. The work of Stucki et al. [44] for lower temperature operation and the work of Chakinala et al. [52] for higher temperatures. Note: Gas molar compositions were rounded out and the term 'ND' refers to values below 0.1 or non-detected.

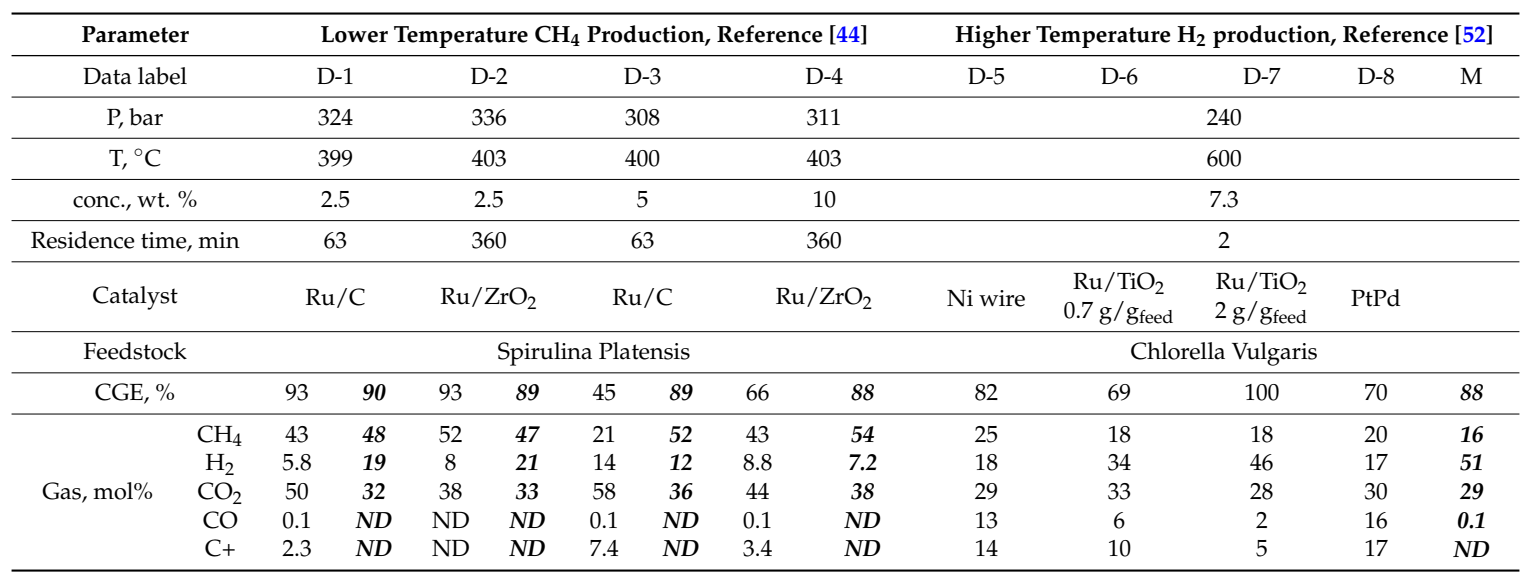

As expected for the lower temperature processing conditions, the model $\mathrm{CH}_{4}$ molar prediction showed better conformity with the higher carbon conversion datasets D-1 and D-2 than that of D-3 and D-4. The predicted $\mathrm{H}_{2}$ concentration was clearly distorted by the $\mathrm{CH}_{4}$ favorable catalytic activity of ruthenium, a similar conclusion was found when model results were compared to the work of Haiduc et al. [43]. Another reason behind the model distortion compared to D-3 and D-4 was the detected molar composition of heavier hydrocarbons $\mathrm{C}+$ in the experimental runs, which indicates incomplete conversion into the expected equilibria gases. A limited carbon gasification rate was reported, as low as $45 \%$ in D-3, something that is expected at such lower temperature conditions and shorter residence times [6]. When analyzing D-3 and D-4, both cases with increased solid throughput, a condition needed to favor $\mathrm{CH}_{4}$ production, longer residence times that enable complete decomposition of solid organics into equilibrium gases is needed. To illustrate further, a look at the total carbon gas yields (not shown in the table), the model ( $90 \%$ CGE) with a $0.29 \mathrm{~g} / \mathrm{g}_{\text {feed }}$ compared favorable to D-1 (93\% CGE) with $0.26 \mathrm{~g} / \mathrm{g}_{\text {feed }}$ than D-3 (45\% CGE) with $0.09 \mathrm{~g} / \mathrm{g}_{\text {feed }}$.

For the higher temperature conditions, Chakinala et al. [52] performed a parametric analysis with a capillary tube reactor setup. The model validation for $\mathrm{H}_{2}$ production across varied processing conditions was shown in our earlier publication [20]. Chakinala et al. [52] investigated the effect of catalyst nature on the product as shown in the variation of CGE and product gas composition within data sets D-5 to D-8. The higher reported CGE values lead to better conformity by the model data set-M. D-7 with excess loading of a ruthenium based catalysts $2 \mathrm{~g} / \mathrm{g}_{\text {feed }}$, recorded complete carbon partitioning into gas phase and had an almost identical representation of $\mathrm{H}_{2}$ and $\mathrm{CH}_{4}$ molar compositions to that of the model. The reported C+ (heavier hydrocarbon) composition, despite minimal compared to that of D-5, D-6 and D-8, showed that gas reforming equilibrium was still not achieved. Hydrocarbon reforming and gas phase reactions such as steam reforming and water gas shift activity are reported to take place after a much longer residence time than that reportedly set in the current experimental setup $[4,5,7,11]$. As such, it could be concluded that the modelling approach is capable of illustrating reasonably accurate predictions to the product gas nature as well as reactor yields from an algal slurry, for appropriate reactor setup conditions, that enable complete carbon conversion and gas formation equilibria. On a more conservative interpretation of the model findings, the thermo-chemical processing limit for chemical fuel production could be estimated. Similar approaches have been adapted in literature and were also validated with other available experimental data sets for a wide variety of biomass $[31,35,36,46]$. 


\subsection{Conceptual Plant Simulation-Mass Balance}

\subsubsection{Upstream Processing}

Influence of Solid Throughput

Alteration in the SCWG product nature for all cases is a result of the variation within the principal conversion block A2, and is attributed to the influence of both slurry solid throughput and the SCWG reactor operating temperature for each case. Table 6 shows a summary of the mass balance main assumptions and findings for the upstream processing of the four cases studied. When comparing the hydrogen cases with the BioSNG base case, all of which have identical upstream processing and a SCWG reactor temperature of $600{ }^{\circ} \mathrm{C}$, the influence of increased solid throughput to the pumping limit of $18 \%$, is significant. First, this leads, on a $\mathrm{kg}$ per $\mathrm{kg}$ of organic feed basis, to almost double the direct $\mathrm{CH}_{4}$ mass yield from 0.14 for the hydrogen cases to 0.27 in the BioSNG base case, while dropping the $\mathrm{H}_{2}$ yield by three times from 0.09 to 0.03 . In literature [6], this was attributed to the general stoichiometric balance for hydrogen formation from biomass, which requires water as a reactant. The non-linearity rate at which carbon content, within the increased slurry throughput, displaces available reactive hydrogen and oxygen from aqueous processing, disfavors hydrogen formation for that of methane, carbon oxides and unconverted carbon.

The resulting water content in the SCWG product influences subsequent processing and upgrading as well. Despite higher water consumption (shown as reactive water in Table 6), as a reactant for the hydrogen cases, the SCWG product water content remains higher than that of the BioSNG cases. This leads to a lower expander discharge temperature, $367^{\circ} \mathrm{C}$ compared to $377^{\circ} \mathrm{C}$ for the BioSNG case in block A3. This is mainly due to the higher specific heat capacity of water compared to that of the organic gases under supercritical conditions. Also, the higher water content leads to an enhanced acid gas scrubbing effect within the subsequent pressurized flash separator. The $\mathrm{CO}_{2}$ and $\mathrm{H}_{2} \mathrm{~S}$ recovery into the dry gas increased from $77.1 \%$ and $63.4 \%$ in the hydrogen cases to $90.7 \%$ and $83.5 \%$, respectively, for the BioSNG base case with a lower water content. Previous publications $[27,34]$ have stated that in order to achieve complete separation of acid gases, further additional water is needed, a configuration that was not under consideration in this study. It is worth mentioning here, that albeit in a much less significant magnitude than for the acid gases, the higher water content also lead to lower $\mathrm{H}_{2}$ and $\mathrm{CH}_{4}$ recovery in the dry gas, with both decreasing by 0.7 and 1 percentage point respectively, and as such a crucial design trade-off is present.

Subsequent gas cleaning is a pre-requirement for downstream processing to reduce the unnecessary acid gas flow, namely $\mathrm{CO}_{2}$, as well as to avoid catalyst poisoning and equipment corrosion caused by the sulfur compounds. The logic behind the design of a gas separation system that considers an acid gas removal unit rather than further scrubbing of the product gas is to avoid processing losses of target gases $\left(\mathrm{H}_{2}\right.$ and $\left.\mathrm{CH}_{4}\right)$ within effluent water. For an industrial Selexol unit, at which $\mathrm{H}_{2}$ is not soluble in the MDEA solvent, $\mathrm{H}_{2}$ purity reaches $79 \%$ in the product syngas compared to an almost $52 \%$ $\mathrm{CH}_{4}$ purity achieved with the BioSNG base case. As a result of the higher downstream upgrading loads required for the BioSNG case, the processing penalty is more significant than that for the hydrogen cases. An additional advantage for the selected Selexol unit is maintaining elevated pressure levels and as a result eliminates the need for further gas recompression downstream. 
Table 6. Main modelling settings and simulation findings of the mass balance for the upstream processing for the different case studies. 'N/A': not applicable.

\begin{tabular}{|c|c|c|c|c|c|}
\hline \multicolumn{2}{|l|}{ Case Study } & $\begin{array}{l}\text { Hydrogen } \\
\text { Base Case }\end{array}$ & $\begin{array}{c}\text { Hydrogen } \\
\text { 2nd Case }\end{array}$ & $\begin{array}{l}\text { BioSNG } \\
\text { Base Case }\end{array}$ & $\begin{array}{l}\text { BioSNG } \\
\text { 2nd Case }\end{array}$ \\
\hline \multicolumn{2}{|c|}{ Slurry solid conc., wt. \% } & \multicolumn{2}{|c|}{$5 \%$} & \multicolumn{2}{|c|}{$18 \%$} \\
\hline \multicolumn{6}{|c|}{ Feed Pretreatment-block A1 } \\
\hline \multicolumn{2}{|l|}{ Slurry outlet $\mathrm{P}$, bar } & \multicolumn{4}{|c|}{250} \\
\hline \multicolumn{2}{|l|}{ Slurry outlet $\mathrm{T},{ }^{\circ} \mathrm{C}$} & \multicolumn{4}{|c|}{350} \\
\hline \multicolumn{6}{|c|}{ SCWG Three step Reactor System-block A2 } \\
\hline \multicolumn{2}{|c|}{ Hydrolysis reactor $\mathrm{T},{ }^{\circ} \mathrm{C}$} & \multicolumn{4}{|c|}{350} \\
\hline Salt separator inlet $\mathrm{T}$ & & \multicolumn{4}{|c|}{380} \\
\hline \multicolumn{2}{|c|}{ SCWG reactor inlet $\mathrm{T},{ }^{\circ} \mathrm{C}$} & \multicolumn{3}{|c|}{600} & 450 \\
\hline \multirow{5}{*}{$\begin{array}{l}\text { SCWG product (water content } \\
\text { considered), } \mathrm{mol} \%\end{array}$} & $\mathrm{CH}_{4}$ & & & 6.31 & 7.54 \\
\hline & $\mathrm{H}_{2}$ & & & 5.49 & 1.42 \\
\hline & $\mathrm{CO}_{2}$ & & & 6.53 & 5.77 \\
\hline & $\mathrm{CO}$ & & & 0.21 & 0.02 \\
\hline & $\mathrm{H}_{2} \mathrm{~S}$ & & & 0.05 & 0.05 \\
\hline \multicolumn{2}{|c|}{ Reactive $\mathrm{H}_{2} \mathrm{O}, \mathrm{kg} / \mathrm{kg}_{\text {organicfeed }}$} & & & 0.34 & -0.24 \\
\hline \multicolumn{2}{|c|}{$\mathrm{CH}_{4}$ gas yield, $\mathrm{kg} / \mathrm{kg}_{\text {organicfeed }}$} & & & 0.27 & 0.31 \\
\hline & & & & 0.03 & 0.01 \\
\hline \multicolumn{6}{|c|}{ Heat and Power Recovery-block A3 } \\
\hline \multicolumn{2}{|c|}{ Expander isentropic efficiency- $\eta_{T}, \%$} & \multicolumn{3}{|c|}{92} & $\mathrm{~N} / \mathrm{A}$ \\
\hline \multicolumn{2}{|c|}{ Expander discharge $\mathrm{P}, \mathrm{bar}$} & & 65 & & $\mathrm{~N} / \mathrm{A}$ \\
\hline \multicolumn{2}{|c|}{ Expander discharge $\mathrm{T},{ }^{\circ} \mathrm{C}$} & & & 377 & $\mathrm{~N} / \mathrm{A}$ \\
\hline \multicolumn{2}{|c|}{ Product cooler outlet T, ${ }^{\circ} \mathrm{C}$} & \multicolumn{4}{|c|}{25} \\
\hline \multicolumn{6}{|c|}{ Water Separation-block B1 } \\
\hline 1st stage pressurized $\mathrm{KO} \mathrm{d}$ & , bar & & & & \\
\hline & $\mathrm{CH}_{4}$ & & & 33.5 & 50.2 \\
\hline & $\mathrm{H}_{2}$ & & & 29.2 & 9.42 \\
\hline Dry oas comnosition mol\% & $\mathrm{CO}_{2}$ & & & 31.6 & 34.2 \\
\hline Dry gas composition, mor \% & $\mathrm{CO}$ & & & 1.06 & 0.12 \\
\hline & $\mathrm{H}_{2} \mathrm{~S}$ & & & 0.21 & 0.25 \\
\hline & $\mathrm{H}_{2} \mathrm{O}$ & & & 0.14 & 0.15 \\
\hline $\mathrm{CH}_{4}$ recovery in dry $\mathrm{g}$ & & & & 99.4 & 99.2 \\
\hline $\mathrm{H}_{2}$ recovery in dry ga & & & & 99.6 & 99.5 \\
\hline $\mathrm{CO}_{2}$ recovery in dry $\mathrm{g}$ & & & & 90.7 & 87.8 \\
\hline $\mathrm{H}_{2} \mathrm{~S}$ recovery in dry $\mathrm{g}$ & & & & 83.5 & 79.4 \\
\hline Acid Gas Removal-blo & & & & & \\
\hline Sweet gas composition mol\% & $\mathrm{CH}_{4}$ & & & 51.9 & 75.2 \\
\hline Sweet gas composition, mol\% & $\mathrm{H}_{2}$ & & & 39.8 & 14.7 \\
\hline $\mathrm{CH}_{4}$ recovery in sweet & & & & & \\
\hline $\mathrm{CO}_{2}$ extracted, $\%$ & & & & & \\
\hline $\mathrm{H}_{2} \mathrm{~S}$ extracted, $\%$ & & & & & \\
\hline
\end{tabular}

Influence of SCWG Temperature

The BioSNG 2nd case conforms to economic considerations of lower operating temperatures, at $450{ }^{\circ} \mathrm{C}$ and higher solid throughput, at pumping limits of $18 \mathrm{wt}$. \%. If compared to the BioSNG base case, the influence of lower temperature leads direct $\mathrm{CH}_{4}$ mass yield to increase, from 0.27 to 0.31 on $\mathrm{kg}$ per $\mathrm{kg}$ of organic feed basis (although to a lesser magnitude than the effect of solid content increase from 0.14 to 0.27 ), while the $\mathrm{H}_{2}$ yield drops from 0.03 to $0.01 \mathrm{~kg}$ per $\mathrm{kg}$ of organic feed basis. Another observation for the closer to critical point processing is the negative water consumption, which could be attributed to water released during gas phase methanation reactions taking place. However, it has been reported that the kinetic rate of gas reforming reactions at such temperature levels is considerably slower than decarboxylation and dehydration mechanisms of organic acids and polymers experienced under supercritical water, and as such the latter is predicted to be the source of additional water [5]. This could additionally explain the lower CO concentrations, where the composition increases from 
$0.02 \mathrm{~mol} \%$ within the low temperature 2 nd case to 10 times higher, around $0.2 \mathrm{~mol} \%$ at $600{ }^{\circ} \mathrm{C}$, in the more kinetically driven base case. Also, the lower SCWG operating temperature leads to the elimination of the commercial USC expander in block A3 and the product is directly cooled and fed into the 1st stage $\mathrm{KO}$ drum at an elevated pressure of 60 bar. Slightly lower $\mathrm{CH}_{4}$ and $\mathrm{H}_{2}$ recovery rates are obtained compared to the base case due to varied molar solubility, 0.2 and 0.1 percentage point lower for each respectively. However an improved scrubbing effect is recorded, $88.3 \%$ to $90.7 \%$ dry gas $\mathrm{CO}_{2}$ recovery and $79.7 \%$ to $83.5 \% \mathrm{H}_{2} \mathrm{~S}$ recovery in the base case respectively. Finally, if the final sweet gas product from upstream processing is compared, $\mathrm{CH}_{4}$ purity is higher by almost $150 \%$ in the second case, which significantly decreases the downstream processing load to achieve grid specified conditions.

\subsubsection{Synthetic Natural Gas Cases}

The $\mathrm{CH}_{4}$ enriched dry sweet gas enters the final stage of upgrading in block $\mathrm{C} 1$ to meet the specified grid conditions, mentioned earlier in Table 3. Sequential pressurized membranes recover around $95 \%$ of $\mathrm{CH}_{4}$ within a permeate stream and release the off-gas for indirect production in block C2. Residue hydrogen, carbon oxides, nitrogen and sulfur compounds are extracted in this stage. Identical membrane systems based on established commercial technologies, designed for the higher syngas and impurity throughput in the base case, were applied to both cases for comparative reasons. Table 7 shows a summary of some of the main simulation findings for the BioSNG downstream processing blocks.

Table 7. Main modelling settings and simulation findings of the mass balance for the downstream processing of the BioSNG cases.

\begin{tabular}{|c|c|c|c|}
\hline \multicolumn{2}{|l|}{ Case Study } & Base Case & 2nd Case \\
\hline \multicolumn{4}{|l|}{ Membrane separator system-block C1 } \\
\hline \multicolumn{2}{|l|}{$\mathrm{CH}_{4}$ recovery rate in product gas, $\%$} & \multicolumn{2}{|c|}{95.1} \\
\hline $\mathrm{H}_{2}$ extracted, $\%$ & & \multicolumn{2}{|c|}{99.0} \\
\hline N-compounds extracted, $\%$ & & \multicolumn{2}{|c|}{96.0} \\
\hline $\mathrm{H}_{2} \mathrm{~S}$ extracted, $\%$ & & \multicolumn{2}{|c|}{99.9} \\
\hline Indirect Methanation-block C2 & & & \\
\hline Off-gas feed, $\mathrm{kg} / \mathrm{kg}$ organicfeed & & 0.07 & 0.03 \\
\hline \multirow{4}{*}{ Off-gas composition to methanation, $\mathrm{mol} \%$} & $\mathrm{CH}_{4}$ & 1.23 & 4.53 \\
\hline & $\mathrm{H}_{2}$ & 93.5 & 87.9 \\
\hline & $\mathrm{CO}_{2}$ & 1.96 & 6.13 \\
\hline & $\mathrm{CO}$ & 3.21 & 1.06 \\
\hline $\mathrm{H}_{2} \mathrm{~S}$, ppmv & & 323 & 219 \\
\hline \multicolumn{2}{|l|}{$\mathrm{CO}_{x}$ conversion rate in methanation, $\%$} & 97.4 & 95.7 \\
\hline \multirow{2}{*}{ methanation dry outlet composition, mol\% } & $\mathrm{CH}_{4}$ & 76.8 & 76.7 \\
\hline & $\mathrm{H}_{2}$ & 19.9 & 17.2 \\
\hline \multicolumn{2}{|l|}{$\begin{array}{l}\text { Gross production rate, } \mathrm{kg} / \mathrm{kg}_{\text {organicfeed }} \\
\text { Grid BioSNG composition, mol } \%\end{array}$} & 0.353 & 0.348 \\
\hline $\mathrm{CH}_{4}$ & & 97.7 & 98.4 \\
\hline $\mathrm{H}_{2}$ & & 0.79 & 0.22 \\
\hline $\mathrm{CO}_{2}$ & & 1.09 & 0.93 \\
\hline
\end{tabular}

For block $\mathrm{C} 2$, both off-gas mixing with depleted $\mathrm{CO}_{2}$ rich gas streams (from the upstream water separator and Selexol units) to optimize $\mathrm{H}_{2} / \mathrm{CO}_{x}$ ratio inside the RWGS reactor and the introduction of super-heated steam within the methanation reactor to suppress coke formation, are essential process synthesis steps to maximize the $\mathrm{CH}_{4}$ yield [21]. A similar $\mathrm{CH}_{4}$ purity on dry basis in the methanation outlet was recorded, however the stoichiometric conversion was slightly lower in the 2nd case configuration due to the different $\mathrm{CO}_{x}$ ratios in the off-gas feed. The methanation product stream is recirculated into the membrane system for the adjustment of the final concentration. As a result, 
taking into consideration that both BioSNG products are not identical but are within acceptable grid injection limits, the difference in gross production of BioSNG was only higher by $5 \mathrm{~g} / \mathrm{kg}$ organicfeed in the base case compared to the 2 nd case. This is attributed to the fact that the higher gasification rate in the base case SCWG along with higher carbon conversion rate $~ 97 \%$ in indirect production blocks, lead to the close matching with the direct stoichiometric output of $\mathrm{CH}_{4}$ in the SCWG of the 2nd case. Lastly, it is worth mentioning that the 2nd case produced a higher quality BioSNG product.

\subsubsection{Hydrogen Cases}

The processing difference between the two hydrogen cases under investigation is the operation of the downstream indirect hydrogenation block D2. The upstream operation of the BioSNG base case could be considered a higher solid throughput case for hydrogen production, but as shown earlier in Table 6, this would lead to a lower $\mathrm{H}_{2}$ purity in the direct SCWG product, and as reported in our earlier publication [20], would result in significantly larger downstream processing losses compared to the cases presented here. Table 8 shows a summary of the simulation results where both cases share a direct $\mathrm{H}_{2}$ production rate from the PSA separator block D1, 0.082 at $\mathrm{kg}$ per $\mathrm{kg}$ of organic feed.

Table 8. Main modelling settings and simulation findings of the mass balance for the downstream processing of the hydrogen cases. PSA: Pressure Swing Adsorption. 'N/A': not applicable.

\begin{tabular}{|c|c|c|c|}
\hline Case Study & Base Case & & 2nd Case \\
\hline \multicolumn{4}{|l|}{$\mathrm{H}_{2}$ PSA units-block D1 } \\
\hline $\mathrm{H}_{2}$ recovery in product gas, $\%$ & & 90.00 & \\
\hline $\mathrm{H}_{2}$ purity in product gas, $\%$ & & 99.99 & \\
\hline Direct $\mathrm{H}_{2}$ production, $\mathrm{kg} / \mathrm{kg}$ organicfeed & & 0.082 & \\
\hline \multicolumn{4}{|l|}{ Residue gas composition, $\mathrm{mol} \%$} \\
\hline $\mathrm{CH}_{4}$ & & 52.8 & \\
\hline $\mathrm{H}_{2}$ & & 27.5 & \\
\hline \multicolumn{4}{|l|}{ Indirect hydrogenation - block D2 } \\
\hline \multicolumn{4}{|l|}{ Steam reformer } \\
\hline $\mathrm{CH}_{4}$ conversion rate, $\%$ & 98.7 & & $\mathrm{~N} / \mathrm{A}$ \\
\hline $\mathrm{H}_{2}$ outlet, $\mathrm{mol} \%$ & 71.1 & & $\mathrm{~N} / \mathrm{A}$ \\
\hline CO outlet, $\mathrm{mol} \%$ & 21.4 & & $\mathrm{~N} / \mathrm{A}$ \\
\hline \multicolumn{4}{|l|}{ Water gas shift reactors } \\
\hline Combined CO conversion rate, $\%$ & 97.2 & & $\mathrm{~N} / \mathrm{A}$ \\
\hline $\mathrm{H}_{2}$ outlet, $\mathrm{mol} \%$ & 76.2 & & \\
\hline CO outlet, ppmv & 10 & & $\mathrm{~N} / \mathrm{A}$ \\
\hline Indirect $\mathrm{H}_{2}$ production, $\mathrm{kg} / \mathrm{kg}_{\text {organicfeed }}$ & 0.069 & & $\mathrm{~N} / \mathrm{A}$ \\
\hline
\end{tabular}

For the 2nd case, the residue gas from the PSA unit, rich in $\mathrm{CH}_{4}$, is fed into an in-situ heat generation system, simulated as a gas furnace. For the base case, the residue gas is fed into a methane reformer setup in block D2, a widely deployed commercial technology which includes a subsequent two temperature stage WGS configuration to enhance $\mathrm{H}_{2}$ production. The overall carbon oxides to hydrogen conversion rate within the block is $95.9 \%$. The $\mathrm{H}_{2}$ rich product stream has $76.2 \%$ purity with a balance of mostly $\mathrm{CO}_{2}$ and water. It is subsequently dried and fed into a secondary PSA unit to produce an additional $0.069 \mathrm{~kg}$ per $\mathrm{kg}$ of organic feed of $99.9 \%$ purity hydrogen. The indirect hydrogenation process increases the gross $\mathrm{H}_{2}$ production on mass basis by $184 \%$ compared to the base case.

\subsection{Conceptual Plant Simulation-Energy Balance}

The thermodynamic data of the focal material streams along with energy requirements of major process components for the four cases were collected from the simulation and reported in Table 9 to show the present thermal loads (net heat released) and demand. The distinctive difference between the hydrogen and BioSNG cases is the effect of slurry throughput on the specific heat profiles. In block 
A1, both the demand for slurry pumping to 250 bar and preheat to $350{ }^{\circ} \mathrm{C}$ for the $5 \mathrm{wt}$. \% hydrogen cases was almost 4 times that recorded for the BioSNG cases. Similarly in block A2, the net reactor demand (hydrolysis + gasification) and the internal stepwise heating demand (salt separator heat jacket + SCWG reformer preheater) are significantly higher in the hydrogen cases compared to the BioSNG base case, all of which have a similar SCWG operating temperature of $600{ }^{\circ} \mathrm{C}$. However, it is worth noting that the lower net reactor demand is also partially attributed to the endothermic nature of hydrogen formation pathways at $600{ }^{\circ} \mathrm{C}$ compared to the exothermic nature experienced with $\mathrm{CH} 4$ formation $[7,9]$. If the two BioSNG cases are compared, the influence of the SCWG reactor temperature at $450{ }^{\circ} \mathrm{C}$ for the 2 nd case plays an additional role in the lower demand. Logically, the interstage heating is lower and also the net reactor heat demand.

Table 9. Main modelling settings and simulation findings of the energy balance for the upstream processing for the different case studies. All units are MW per $M W_{L H V}$ of feed, unless stated otherwise. 'N/A': not applicable.

\begin{tabular}{|c|c|c|c|c|}
\hline Case Study & $\begin{array}{l}\text { Hydrogen } \\
\text { Base Case }\end{array}$ & $\begin{array}{l}\text { Hydrogen } \\
\text { 2nd Case }\end{array}$ & $\begin{array}{c}\text { BioSNG } \\
\text { Base Case }\end{array}$ & $\begin{array}{l}\text { BioSNG } \\
\text { 2nd Case }\end{array}$ \\
\hline Plant feedstock input, $M W_{L H V}$ & \multicolumn{2}{|c|}{105.8} & \multicolumn{2}{|c|}{308.9} \\
\hline \multicolumn{5}{|l|}{ Feed pretreatment block-A1 } \\
\hline Slurry pump demand & \multicolumn{2}{|c|}{0.037} & \multicolumn{2}{|c|}{0.009} \\
\hline Slurry preheater demand & \multicolumn{2}{|c|}{1.478} & \multicolumn{2}{|c|}{0.381} \\
\hline SCWG Three step reactor block-A2 & & & & \\
\hline Net reactor demand & \multicolumn{2}{|c|}{0.777} & 0.146 & 0.124 \\
\hline Interstage heating demand & \multicolumn{2}{|c|}{0.652} & 0.242 & 0.111 \\
\hline \multicolumn{5}{|l|}{ Heat and power recovery block- $A 3$} \\
\hline Expander load & \multicolumn{2}{|c|}{0.321} & 0.088 & $\mathrm{~N} / \mathrm{A}$ \\
\hline Product cooler load & \multicolumn{2}{|c|}{2.382} & 0.578 & 0.569 \\
\hline \multicolumn{5}{|c|}{ Downstream hydrogen pathway blocks-D1 and D2 } \\
\hline Steam reformer demand & 0.088 & $\mathrm{~N} / \mathrm{A}$ & & \\
\hline Water gas shift load & 0.016 & $\mathrm{~N} / \mathrm{A}$ & & \\
\hline Steam generation demand & 0.049 & $\mathrm{~N} / \mathrm{A}$ & & \\
\hline Net downstream power load & 0.007 & 0.007 & & \\
\hline Residue gas heat recovery & 0.064 & 0.305 & & \\
\hline Gross $\mathrm{H}_{2}$ production & 0.855 & 0.463 & & \\
\hline Split $\mathrm{H}_{2}$ indirect product, $\%$ & 46 & 0 & & \\
\hline \multicolumn{5}{|l|}{ Downstream BioSNG pathway blocks-C1 and $\mathrm{C} 2$} \\
\hline Methantion reactor load & & & 0.036 & 0.009 \\
\hline Steam generation demand & & & 0.058 & 0.015 \\
\hline Net downstream power demand & & & 0.016 & 0.004 \\
\hline Residue gas heat recovery load & & & 0.051 & 0.048 \\
\hline Gross BioSNG production & & & 0.738 & 0.728 \\
\hline Split BioSNG indirect product, \% & & & 21 & 6 \\
\hline
\end{tabular}

In block A3, the USC expander for the hydrogen cases produces both higher specific and gross power loads due to the higher water content in the SCWG product, which as mentioned in Section 3.1.2, due to fluid crossover of the water critical point, enables higher thermal extraction. Earlier publications reported that power extraction in the expander competes directly with heat recuperation from the SCWG product $[37,40]$. However, with the current configuration for power extraction from the SCWG product with the USC expander only, across the supercritical point without any further reheat, the rate of power extracted in the expander is only $\sim 13 \%$ and $~ 15 \%$ of the total amount of thermal energy that potentially could be recuperated from the SCWG product in the hydrogen and BioSNG base case respectively.

Another interesting observation for the BioSNG cases; with the elevation of the SCWG reactor temperature from 450 to $600{ }^{\circ} \mathrm{C}$, albeit lower direct BioSNG purity in the SCWG product (as shown in Table 6), an almost equivalent thermal recovery is achieved. The difference in potential thermal energy recovery between the base case, which includes both the USC expander and product cooler 


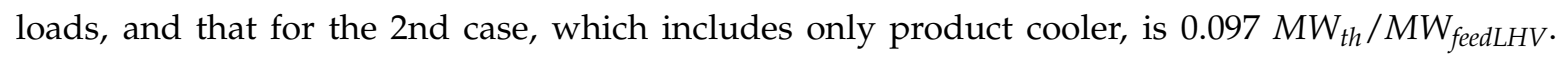
While the difference for the gross direct BioSNG production between both cases is only 0.101 $M W_{L H V} / M W_{f e e d L H V}$. From this, it could be concluded that the elevation of SCWG reactor temperature enables a poly-generative nature of the bio-refinery, with minimal influence on the gross energy production. Further scrutiny to such a hypothesis, which is dependable on the internal heat recovery system will be covered in the following heat integration analysis section. However, such finding still attests to the advantageous nature of aqueous processing which allows a potential for process integration with available industrial waste streams to yield a diverse set of energy products without reduction to the overall gross production.

For downstream processing, the 2nd hydrogen case configured for the purpose of in-situ heat generation from residue gas, records almost 5 times equivalent the base case recovered heat. While the latter, with indirect production, had a gross $\mathrm{H}_{2}$ product of $0.855 \mathrm{MW}_{\mathrm{LHV}} / \mathrm{MW}_{\text {feedLHV }}$ compared to only 0.463 for the base case. Some of the major thermal load and demand, such as the steam reformer and steam generator, for the base case downstream processing units are reported in Table 9. It is worth noting that both cases had an almost identical specific downstream gas recompression demands for the PSA systems. This is a result of an almost identical gas composition between the direct syngas produced and the indirect $\mathrm{H}_{2}$ rich stream. However, the authors acknowledge that this is a result of the simulation settings, while in practice, the dissimilar flow rates between both cases would deem such a finding challenging to achieve feasibly. With regards to the BioSNG cases, the presence of a lower purity SCWG product in the base case led to a higher gas residue flow and as a result a significantly higher thermal and power demand within downstream processing (almost by 4 times of the 2nd case). It is worth mentioning, that the configuration for the 2nd case had a $94 \%$ direct production rate in the SCWG reactor compared to the $79 \%$ recorded for the base case.

\subsection{Heat Integration Analysis}

The developed grand composite curves from the pinch analysis are shown in Figure 3, which illustrates the maximum heat recovery and minimum utility demand and Figure 4, which illustrates the distribution of major thermal loads and demands within the four cases. The process pinch point for the hydrogen cases along with the BioSNG base case was allocated at the USC expander outlet. While if compared to the BioSNG 2nd case, the pinch was located at the outlet of the SCWG reactor at $450{ }^{\circ} \mathrm{C}$. The exclusion of power extraction in the latter case, allows higher internal energy recovery within the supercritical conditions. As mentioned in the previous section, in the three cases with power generation, electricity extracted accounted for around $13 \%$ of potential recuperated thermal energy. However the current power extraction configuration (at SCWG reactor outlet conditions) creates a thermal demand at the processing bottleneck of supercritical conditions. For the BioSNG 2nd case, the higher pinch point reduced the hot utility by almost a third from 0.31 in the base case to 0.11 $M W_{t h} / M W_{f e e d L H V}$ and the cold utility by a half from 0.23 to $0.12 M W_{t h} / M W_{f e e d L H V}$. This leads to an opportunity for an overall lower thermal penalty, however it comes along with a reduced potential for the lower temperature production of district heating, as can be seen in Figure 3. Although it is worth noting that the presence of thermal pockets under the pinch with the BioSNG 2nd case, could open opportunities for liquid power extractions units, similar to those employed in the Liquefied Natural Gas (LNG) industry. A configuration that was not under consideration in this study.

When comparing the hydrogen cases to the BioSNG base case, the influence of increased solid throughput in the latter leads to significantly lower utility demands, as shown in Figure 3. Despite that the net endothermic SCWG reactor demand for all four cases was above the pinch, as shown in Figure 4, the slightly exothermic $\mathrm{CH}_{4}$ formation reactions in the downstream BioSNG base case lead to a lowered demand at $600{ }^{\circ} \mathrm{C}$ from 82.3 to $55.6 \mathrm{MW}$, corresponding with the solid content increase from $5 \mathrm{wt}$. \% to $18 \mathrm{wt}$. \%. The more favorable conditions in the BioSNG 2nd case with a lowered temperature of $450{ }^{\circ} \mathrm{C}$ further reduced the demand to just $47.2 \mathrm{MW}$ only, which is $57 \%$ of that for the hydrogen favorable conditions. The higher process pinch for the BioSNG 2nd case maximized the 
thermal recovery in the upstream supercritical processing of the plant, as the interstage heating and salt separator demand was only 3.25 MW, compared to more than $60 \mathrm{MW}$ for each of the other cases.

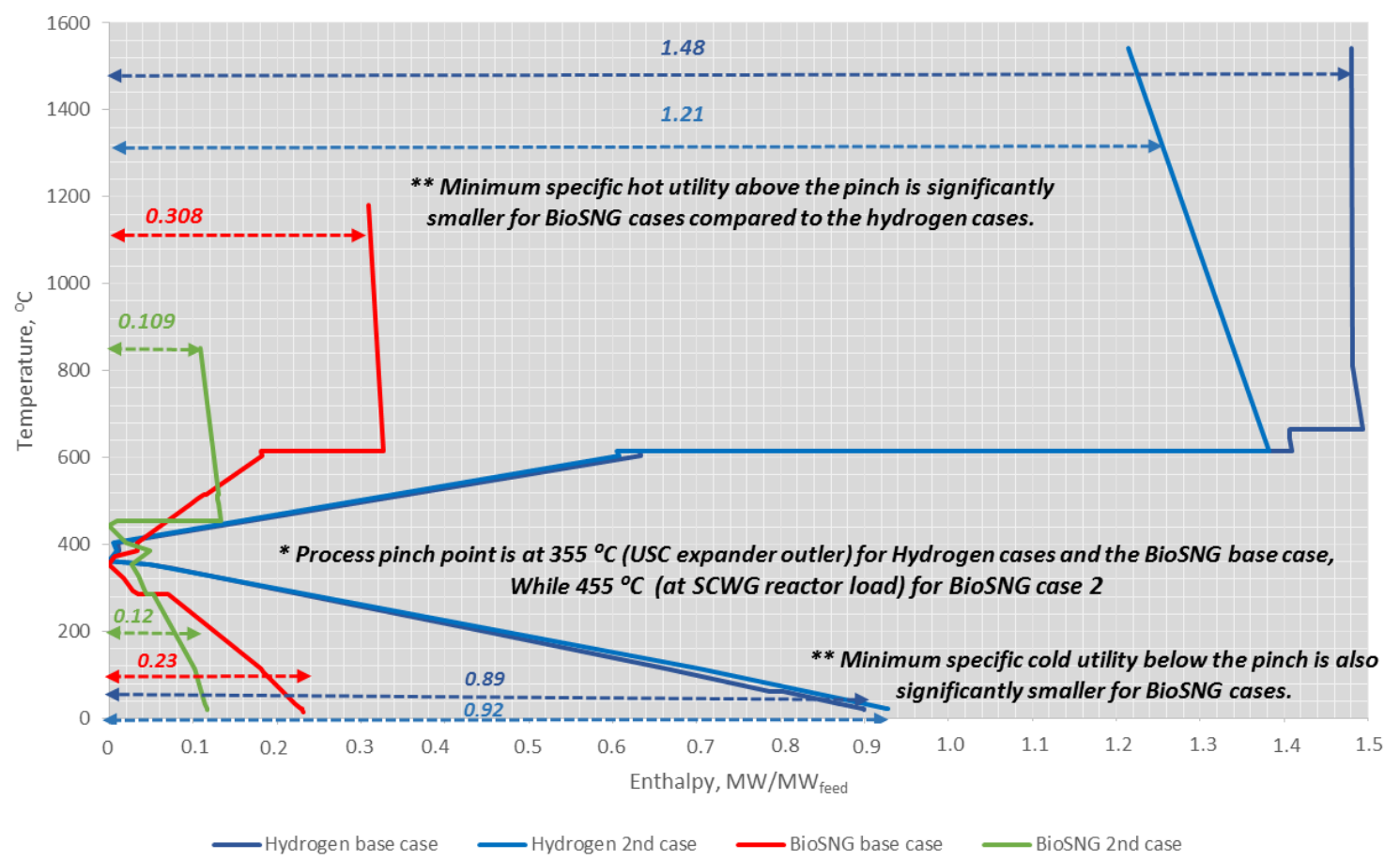

Figure 3. Comparative assessment of the process pinch along with minimum utility demands (dotted lines) plotted on the grand composite curves for all cases.

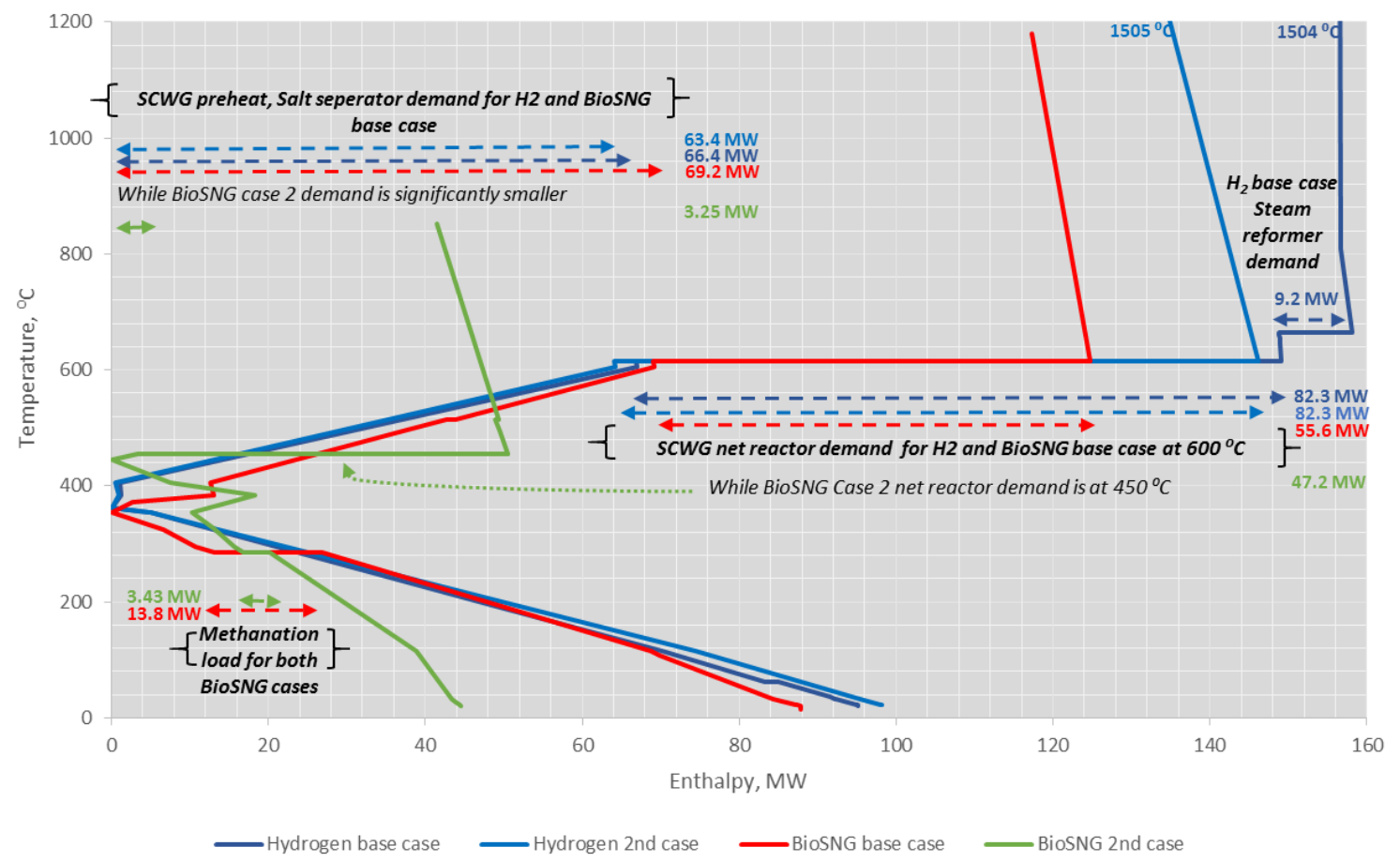

Figure 4. Comparative assessment of the major thermal loads and demand plotted on the grand composite curves for all four case studies. The dotted lines are an illustration of the thermal range for some of the components for each case. 
The onsite thermal recovery (available from process residue gases), also leads to the hydrogen 2nd case (with no indirect production) recording a lower interstage heating and salt separator demand than the other two base cases with $600{ }^{\circ} \mathrm{C}$ reactor conditions. However, onsite heat generation in this case amounted to only around $8 \%$ of the above pinch net reactor demand, as shown in Table 9 . As such, the replacement of downstream indirect production with in-situ heat generation reduced the minimum hot utility demand by $0.27 \mathrm{MW}_{t h} / \mathrm{MW}_{\text {feedLHV }}$ compared to the base case, while reducing the gross $\mathrm{H}_{2}$ output by almost a half, a trade-off that requires additional economic scrutiny. For the BioSNG 2nd case, the lower SCWG reactor temperature led to the lower hot utility requirement, however also led to the exclusion of in-situ power production and less heat available for district heat production.

Table 10 shows a summary of the thermal performance for all four cases based on integrated syngas production along with onsite CHP configuration. The energetic efficiency evaluated the case studies on the absolute amount of recoverable coproducts, while the fuel equivalent efficiency considered the CHP products based on reference technologies and exergetic efficiency considered the thermodynamic quality for each product. In terms of syngas production, the 2 nd hydrogen case recorded the lowest gross production (organic recovery rate) at $0.463 M W_{L H V}$ per $M W_{\text {feed } L H V}$ compared to the three other cases due to the absence of indirect production. For the two base cases, the hydrogen case recorded higher gross production due to the lower conversion rates (or higher processing losses) in downstream indirect production of the BioSNG cases.

Table 10. Comparative assessment for the selected case studies.

\begin{tabular}{ccccc}
\hline Performance Parameter & $\begin{array}{c}\text { Hydrogen } \\
\text { Base Case }\end{array}$ & $\begin{array}{c}\text { Hydrogen 2nd } \\
\text { Case }\end{array}$ & $\begin{array}{c}\text { BioSNG Base } \\
\text { Case }\end{array}$ & $\begin{array}{c}\text { BioSNG } \\
\text { 2nd Case }\end{array}$ \\
\hline $\begin{array}{c}\text { Gross syngas product, } \\
M W_{L H V} / M W_{\text {feedLHV }}\end{array}$ & 0.855 & 0.463 & 0.738 & 0.729 \\
$\quad \begin{array}{l}\text { Net syngas product, } \\
M W_{L H V} / M W_{\text {feedLHV }}\end{array}$ & 0.345 & 0.199 & 0.458 & 0.622 \\
$\quad \begin{array}{c}\text { Energetic efficiency, \% } \\
\text { Fuel-equivalent efficiency, \% }\end{array}$ & 55.29 & 42.27 & 59.04 & 66.46 \\
Exergetic efficiency, \% & 65.14 & 52.74 & 63.01 & 66.21 \\
\hline
\end{tabular}

Auxiliary heat generation for all cases was simulated as combustion of additional LEA feedstock to meet the minimum hot utility demand, after dropping the moisture content to $50 \%$. As a result, the hydrogen base case recorded a lower net syngas product recovery rate compared to the BioSNG base case due to the higher quality and quantity of thermal requirements, as shown in Figure 4. The BioSNG 2nd case recorded the highest net syngas recovery rate, due to the lowest utility requirement among the cases, in addition to the $94 \%$ direct production rate which reduced the influence of downstream processing losses (which are more efficient in the hydrogen cases). In terms of overall plant efficiencies, the hydrogen 2 nd case recorded the lowest efficiencies and is mostly penalized for the in-situ combustion of product gas residue. Such a design configuration accounts for a processing loss footprint higher than that for a drying load in auxiliary utility generation for the other cases.

If the base cases are compared (operating similarly at $600^{\circ} \mathrm{C}$ ), the higher net power output and district heating production in the hydrogen case led to higher fuel-equivalent and exergetic efficiencies, despite the higher syngas recovery rate and energetic efficiency recorded for the BioSNG base case. As such, for a conclusive comparison between hydrogen and BioSNG pathways, further economic considerations should be introduced to evaluate the influence of coproducts nature. While for the BioSNG production pathway considerations, the net negative power (net onsite consumption) for the 2nd case, which is mostly required in the subcritical slurry pumping demand, lowered both the fuel-equivalent and exergetic efficiencies compared to energetic efficiency. However, the lowered efficiencies remained higher than the corresponding base case ones, due to the lower utility demands at lower temperature levels. In conclusion, as shown in Table 10, the 2nd BioSNG recorded higher 
overall efficiencies compared to all other cases, at $66.5 \%, 66.2 \%$ and $57.2 \%$ energetic, fuel-equivalent and exergetic efficiencies respectively.

\section{Conclusions}

Supercritical water has continued to prove in experimental setups to be an expedient processing medium for biomass refining. The higher energetic recovery within the coproducts, either syngas, heat or power, compared to traditional thermal applications, is due to the versatile and advantageous thermo-physical properties of aqueous processing across the critical point of water. The developed three step reactor model has proven to depict the parametric sensitive organic valorization process, to either BioSNG and hydrogen enriched syngas, as those reported in literature. The design, modelling and simulation of conceptual production pathways was conducted using Aspen Plus ${ }^{\mathrm{TM}}$ to perform the mass and energy balance for different integration scenarios of onsite direct syngas production along with CHP and indirect production. This research was an attempt to construe some of the thermal and technical design tradeoffs present within the commercial upscaling of the technology.

The solid organic throughput had a higher magnitude of influence than the SCWG reactor temperature, and shaped some of the more deterministic process thermal design questions. Lower organic content within the plant feedstock would favor direct hydrogen production from SCWG, onsite heat and power production and slightly more efficient extraction of acid gases. The latter reasons lead to hydrogen production, when compared to BioSNG at a similar SCWG reactor temperature, to record higher gross syngas production, qualitative fuel-equivalent and exergetic efficiencies and lower quantative energetic efficiency. However, the lower organic content does not conform to neither economic intuition nor thermal design considerations. The higher organic throughput cases had a more effective internal heat recovery rate and as a result recorded higher net syngas production. The lower operating temperature case at $450{ }^{\circ} \mathrm{C}$, which favored direct BioSNG production, at the upper limit for slurry pumping of $18 \mathrm{wt}$. \% organic content recorded the higher limits of $66.46 \%, 66.21 \%$ and $57.39 \%$ of energetic, fuel-equivalent and exergetic efficiencies respectively.

Acknowledgments: This project work was jointly funded by the Academy of Finland (Grant No. 268222) and the National Counsel of Technological and Scientific Development in Brazil and the Academy of Finland International call CNPq(Br)/AKA(Fi) N.30/2012 Grant 490245/2012-9. The corresponding author would also like to gratefully acknowledge the support and funding for his doctoral research from Fortum foundation-Fortumin Säätiö (Grant No. 2001500084).

Author Contributions: Mohamed Magdeldin developed the reactor model, conceptual plant designs, performed the process simulation and modelling, the overall plant evaluation and manuscript preparation. Thomas Kohl performed the heat integration assessment and calculation, and provided guidance throughout the research work. Cataldo De Blasio and Mika Järvinen provided guidance and process design expertise throughout the project work. Song Won Park and Reinaldo Giudici assisted in manuscript preparation.

Conflicts of Interest: The authors declare no conflict of interest.

\section{References}

1. United Nations Framework Convention on Climate Change-Paris Climate Change Conference-November 2015. Available online: http://unfccc.int/meetings/paris_nov_2015/meeting/8926.php (accessed on 6 January 2016).

2. Chum, H.; Faaij, A.; Moreira, J.; Berndes, G.; Dhamija, P.; Dong, H.; Gabrielle, B.; Eng, A.G.; Lucht, W.; Mapako, M.; et al. IPCC Special Report on Renewable Energy Sources and Climate Change Mitigation; Edenhofer, O., Pichs-Madruga, R., Sokona, Y., Seyboth, K., Matschoss, P., Kadner, S., Zwickel, T., Eickemeier, P., Hansen, G., Schlömer, S., et al., Eds.; Cambridge University Press: Cambridge, UK; New York, NY, USA, 2011; pp. 46-59.

3. Kainiemi, L.; Eloneva, S.; Järvinen, M. An assessment of the uncertainties related to bioenergy applications. Manag. Environ. Qual. 2014, 25, 301-312. [CrossRef]

4. Yakaboylu, O.; Harinck, J.; Smit, K.G.; de Jong, W. Supercritical water gasification of biomass: A literature and technology overview. Energies 2015, 8, 859-894. [CrossRef] 
5. Akiya, N.; Savage, P.E. Roles of water for chemical reactions in high-temperature water. Chem. Rev. 2002, 102, 2725-2750. [CrossRef] [PubMed]

6. Kruse, A. Supercritical water gasification. Biofuels Bioprod. Biorefin. 2008, 2, 415-437. [CrossRef]

7. Kruse, A.; Dahmen, N. Water-A magic solvent for biomass conversion. J. Supercrit. Fluids 2015, 96, 36-45. [CrossRef]

8. Brunner, G. Applications of supercritical fluids. Annu. Rev. Chem. Biomol. Eng. 2010, 1, 321-342. [CrossRef] [PubMed]

9. Loppinet-Serani, A.; Aymonier, C.; Cansell, F. Current and foreseeable applications of supercritical water for energy and the environment. ChemSusChem 2008, 1, 486-503. [CrossRef] [PubMed]

10. Knez, Ž.; Markočič, E.; Hrnčič, M.K.; Ravber, M.; Škerget, M. High pressure water reforming of biomass for energy and chemicals: A short review. J. Supercrit. Fluids 2015, 96, 46-52. [CrossRef]

11. Peterson, A.A.; Vogel, F.; Lachance, R.P.; Fröling, M.; Michael, J.; Antal, J.; Tester, J.W. Thermochemical biofuel production in hydrothermal media: A review of sub- and supercritical water technologies. Energy Environ. Sci. 2008, 1, 32-65. [CrossRef]

12. Patel, B.; Guo, M.; Izadpanah, A.; Shah, N.; Hellgardt, K. A review on hydrothermal pre-treatment technologies and environmental profiles of algal biomass processing. Bioresour. Technol. 2016, 199, 288-299. [CrossRef] [PubMed]

13. Ekpo, U.; Ross, A.B.; Camargo-Valero, M.A.; Williams, P.T. A comparison of product yields and inorganic content in process streams following thermal hydrolysis and hydrothermal processing of microalgae, manure and digestate. Bioresour. Technol. 2016, 200, 951-960. [CrossRef] [PubMed]

14. Modell, M. Gasification and Liquefaction of Forest Products in Supercritical Water. In Fundamentals of Thermochemical Biomass Conversion; Overend, R.P., Milne, T.A., Mudge, L.K., Eds.; Springer: Amsterdam, The Netherlands, 1985; pp. 95-119.

15. Antal, M.J., Jr.; Allen, S.; Lichwa, J.; Schulman, D.; Xu, X. Hydrogen production from high moisture content biomass in supercritical water. In Proceedings of the 1999 U.S. DOE Hydrogen Program Review, NREL/CP-570-26938, Golden, CO, USA, 4-6 May 1999; pp. 1-24.

16. De Blasio, C.; Lucca, G.; Özdenkci, K.; Mulas, M.; Lundqvist, K.; Koskinen, J.; Santarelli, M.; Westerlund, T.; Järvinen, M. A study on supercritical water gasification of black liquor conducted in stainless steel and nickel-chromium-molybdenum reactors. J. Chem. Technol. Biotechnol. 2016, 91, 2664-2678. [CrossRef]

17. Elliott, D.C.; Biller, P.; Ross, A.B.; Schmidt, A.J.; Jones, S.B. Hydrothermal liquefaction of biomass: Developments from batch to continuous process. Bioresour. Technol. 2015, 178, 147-156. [CrossRef] [PubMed]

18. Yoshida, Y.; Dowaki, K.; Matsumura, Y.; Matsuhashi, R.; Li, D.; Ishitani, H.; Komiyama, H. Comprehensive comparison of efficiency and $\mathrm{CO}_{2}$ emissions between biomass energy conversion technologies-Position of supercritical water gasification in biomass technologies. Biomass Bioenergy 2003, 25, 257-272. [CrossRef]

19. Cantero, D.A.; Bermejo, M.D.; Cocero, M.J. Reaction engineering for process intensification of supercritical water biomass refining. J. Supercrit. Fluids 2015, 96, 21-35. [CrossRef]

20. Magdeldin, M.; Kohl, T.; Jarvinen, M. Process modeling, synthesis and thermodynamic evaluation of hydrogen production from hydrothermal processing of lipid extracted algae integrated with a downstream reformer conceptual plant. Biofuels 2016, 7, 97-116. [CrossRef]

21. Magdeldin, M.; Kohl, T.; De Blasio, C.; Järvinen, M. Heat integration assessment for the conceptual plant design of synthetic natural gas production from supercritical water gasification of spirulina algae. In Proceedings of ECOS 2015-The 28th International Conference on Efficiency, Cost, Optimization, Simulation and Environmental Impact of Energy Systems, Pau, France, 29 June-3 July 2015.

22. Boukis, N.; Galla, U.; Müller, H.; Dinjus, E. Biomass gasification in supercritical water. Experimental progress achieved with the VERENA pilot plant. In Proceedings of the 15th European Conference \& Exhibition, Berlin, Germany, 7-11 May 2007; pp. 1013-1016.

23. Xiao, P.; Guo, L.; Zhang, X.; Zhu, C.; Ma, S. Continuous hydrogen production by biomass gasification in supercritical water heated by molten salt flow: System development and reactor assessment. Int. J. Hydrog. Energy 2013, 38, 12927-12937. [CrossRef]

24. Marias, F.; Letellier, S.; Cezac, P.; Serin, J.P. Energetic analysis of gasification of aqueous biomass in supercritical water. Biomass Bioenergy 2011, 35, 59-73. [CrossRef] 
25. Feng, W.; van der Kooi, H.J.; de Swaan Arons, J. Biomass conversions in subcritical and supercritical water: Driving force, phase equilibria, and thermodynamic analysis. Chem. Eng. Process. Process Intensif. 2004, 43, 1459-1467. [CrossRef]

26. Tang, H.; Kitagawa, K. Supercritical water gasification of biomass: Thermodynamic analysis with direct Gibbs free energy minimization. Chem. Eng. J. 2005, 106, 261-267. [CrossRef]

27. Lu, Y.; Guo, L.; Zhang, X.; Yan, Q. Thermodynamic modeling and analysis of biomass gasification for hydrogen production in supercritical water. Chem. Eng. J. 2007, 131, 233-244. [CrossRef]

28. Voll, F.A.P.; Rossi, C.C.R.S.; Silva, C.; Guirardello, R.; Souza, R.O.M.A.; Cabral, V.F.; Cardozo-Filho, L. Thermodynamic analysis of supercritical water gasification of methanol, ethanol, glycerol, glucose and cellulose. Int. J. Hydrog. Energy 2009, 34, 9737-9744. [CrossRef]

29. Castello, D.; Fiori, L. Supercritical water gasification of biomass: Thermodynamic constraints. Bioresour. Technol. 2011, 102, 7574-7582. [CrossRef] [PubMed]

30. Freitas, A.C.D.; Guirardello, R. Thermodynamic analysis of supercritical water gasification of microalgae biomass for hydrogen and syngas production. Chem. Eng. Trans. 2013, 32, 553-558.

31. Louw, J.; Schwarz, C.E.; Knoetze, J.H.; Burger, A.J. Thermodynamic modelling of supercritical water gasification: Investigating the effect of biomass composition to aid in the selection of appropriate feedstock material. Bioresour. Technol. 2014, 174, 11-23. [CrossRef] [PubMed]

32. Susanti, R.F.; Dianningrum, L.W.; Yum, T.; Kim, Y.; Lee, Y.-W.; Kim, J. High-yield hydrogen production by supercritical water gasification of various feedstocks: Alcohols, glucose, glycerol and long-chain alkanes. Chem. Eng. Res. Des. 2014, 92, 1834-1844. [CrossRef]

33. Tushar, M.S.H.K.; Dutta, A.; Xu, C. Simulation and kinetic modeling of supercritical water gasification of biomass. Int. J. Hydrog. Energy 2015, 40, 4481-4493. [CrossRef]

34. Gasafi, E.; Reinecke, M.-Y.; Kruse, A.; Schebek, L. Economic analysis of sewage sludge gasification in supercritical water for hydrogen production. Biomass Bioenergy 2008, 32, 1085-1096. [CrossRef]

35. Fiori, L.; Valbusa, M.; Castello, D. Supercritical water gasification of biomass for $\mathrm{H}_{2}$ production: Process design. Bioresour. Technol. 2012, 121, 139-147. [CrossRef] [PubMed]

36. Withag, J.A.M.; Smeets, J.R.; Bramer, E.A.; Brem, G. System model for gasification of biomass model compounds in supercritical water-A thermodynamic analysis. J. Supercrit. Fluids 2012, 61, 157-166. [CrossRef]

37. Galera, S.; Gutiérrez Ortiz, F.J. Techno-economic assessment of hydrogen and power production from supercritical water reforming of glycerol. Fuel 2015, 144, 307-316. [CrossRef]

38. Gutiérrez Ortiz, F.J.; Ollero, P.; Serrera, A.; Sanz, A. Thermodynamic study of the supercritical water reforming of glycerol. Int. J. Hydrog. Energy 2011, 36, 8994-9013. [CrossRef]

39. Aziz, M. Integrated supercritical water gasification and a combined cycle for microalgal utilization. Energy Convers. Manag. 2015, 91, 140-148. [CrossRef]

40. Gassner, M.; Vogel, F.; Heyen, G.; Maréchal, F. Optimal process design for the polygeneration of SNG, power and heat by hydrothermal gasification of waste biomass: Thermo-economic process modelling and integration. Energy Environ. Sci. 2011, 4, 1726-1741. [CrossRef]

41. Valderrama, J.O. The State of the Cubic Equations of State. Ind. Eng. Chem. Res. 2003, 42, $1603-1618$. [CrossRef]

42. Brandenberger, M.; Matzenberger, J.; Vogel, F.; Ludwig, C. Producing synthetic natural gas from microalgae via supercritical water gasification: A techno-economic sensitivity analysis. Biomass Bioenergy 2013, 51, $26-34$. [CrossRef]

43. Haiduc, A.G.; Brandenberger, M.; Suquet, S.; Vogel, F.; Bernier-Latmani, R.; Ludwig, C. SunCHem: An integrated process for the hydrothermal production of methane from microalgae and $\mathrm{CO}_{2}$ mitigation. J. Appl. Phycol. 2009, 21, 529-541. [CrossRef]

44. Stucki, S.; Vogel, F.; Ludwig, C.; Haiduc, A.G.; Brandenberger, M. Catalytic gasification of algae in supercritical water for biofuel production and carbon capture. Energy Environ. Sci. 2009, 2, 535-541. [CrossRef]

45. Ji, P.; Feng, W.; Chen, B.; Yuan, Q. Finding appropriate operating conditions for hydrogen purification and recovery in supercritical water gasification of biomass. Chem. Eng. J. 2006, 124, 7-13. [CrossRef] 
46. Yakaboylu, O.; Harinck, J.; Smit, K.G.; de Jong, W. Supercritical water gasification of biomass: A detailed process modeling analysis for a microalgae gasification process. Ind. Eng. Chem. Res. 2015, 54, 5550-5562. [CrossRef]

47. Mian, A.; Ensinas, A.V.; Marechal, F. Multi-objective optimization of SNG production from microalgae through hydrothermal gasification. Comput. Chem. Eng. 2015, 76, 170-183. [CrossRef]

48. Elliott, D.C. Review of recent reports on process technology for thermochemical conversion of whole algae to liquid fuels. Algal Res. 2016, 13, 255-263. [CrossRef]

49. Kouhia, M.; Holmberg, H.; Sonck, M.; Ahtila, P. Energy analysis of algae-to-biofuel production chains integrated with a combined heat and power plant. In Proceedings of the 23rd European Biomass Conference \& Exhibition-EUBCE, Vienna, Austria, 1-4 June 2015.

50. Berglin, E.J.; Enderlin, C.W.; Schmidt, A.J. Review and Assessment of Commercial Vendors/Options for Feeding and Pumping Biomass Slurries for Hydrothermal Liquefaction; Report Number: PNNL-21981; Pacific Northwest National Laboratory (PNNL): Richland, WA, USA, 2012.

51. Minowa, T.; Sawayama, S. A novel microalgal system for energy production with nitrogen cycling. Fuel 1999, 78, 1213-1215. [CrossRef]

52. Chakinala, A.G.; Brilman, D.W.F.; van Swaaij, W.P.M.; Kersten, S.R.A. Catalytic and non-catalytic supercritical water gasification of microalgae and glycerol. Ind. Eng. Chem. Res. 2010, 49, 1113-1122. [CrossRef]

53. Patzelt, D.J.; Hindersin, S.; Elsayed, S.; Boukis, N.; Kerner, M.; Hanelt, D. Hydrothermal gasification of Acutodesmus obliquus for renewable energy production and nutrient recycling of microalgal mass cultures. J. Appl. Phycol. 2015, 27, 2239-2250. [CrossRef]

54. Frank, E.D.; Elgowainy, A.; Han, J.; Wang, Z. Life cycle comparison of hydrothermal liquefaction and lipid extraction pathways to renewable diesel from algae. Mitig. Adapt. Strateg. Glob. Chang. 2012, 18, 137-158. [CrossRef]

55. Onwudili, J.A.; Lea-Langton, A.R.; Ross, A.B.; Williams, P.T. Catalytic hydrothermal gasification of algae for hydrogen production: Composition of reaction products and potential for nutrient recycling. Bioresour. Technol. 2013, 127, 72-80. [CrossRef] [PubMed]

56. Phyllis2-Database for Biomass and Waste. Available online: https://www.ecn.nl/phyllis2/ (accessed on 14 July 2015).

57. Bejan, A.; Tsatsaronis, G.; Moran, M. Thermal Design and Optimization, 1st ed.; John Wiley \& Sons: New York, NY, USA, 1996.

58. Yakaboylu, O.; Harinck, J.; Smit, K.G.; de Jong, W. Testing the constrained equilibrium method for the modeling of supercritical water gasification of biomass. Fuel Process. Technol. 2015, 138, 74-85. [CrossRef] 